"This is the peer reviewed version of the following article: Mottier P, Tremblay R, Rogers CA (2018), "Seismic retrofit of low-rise steel buildings in Canada using rocking steel braced frames", Journal of

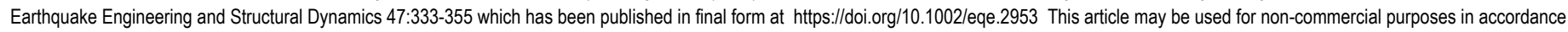
with Wiley Terms and Conditions for Use of Self-Archived Versions"

\title{
Seismic retrofit of low-rise steel buildings in Canada using rocking steel braced frames
}

\author{
Paul Mottier ${ }^{1}$, Robert Tremblay ${ }^{2}$, and Colin Rogers ${ }^{3}$ \\ ${ }^{1}$ Graduate Researcher, ${ }^{2}$ Professor, Department of Civil, Geological and Mining Engineering, Polytechnique \\ Montreal, Montreal, Canada \\ ${ }^{3}$ Associate, Professor, Department of Civil Engineering and Applied Mechanics, McGill University, Montreal, \\ Canada
}

\begin{abstract}
This article examines the use of rocking steel braced frames for the retrofit of existing seismically deficient steel building structures. Rocking is also used to achieve superior seismic performance to reduce repair costs and disruption time after earthquakes. The study focuses on low-rise buildings for which re-centring is solely provided by gravity loads rather than added post-tensioning elements. Friction energy dissipative (ED) devices are used to control drifts. The system is applied to 2- and 3-storey structures located in two seismically active regions of Canada. Firm ground and soft soil conditions are considered. The seismic performance of the retrofit scheme is evaluated using nonlinear dynamic analysis and ASCE 41-13. For all structures, rocking permits to achieve immediate occupancy performance under $2 \%$ in 50 years seismic hazard if the braces and their connections at the building's top storeys are strengthened to resist amplified forces due to higher mode response. Base shears are also increased due to higher modes. Impact at column bases upon rocking induces magnified column forces and vertical response in the gravity system. Friction $\mathrm{ED}$ is found more effective for drift control than systems with ring springs or bars yielding in tension. Drifts are sufficiently small to achieve position retention performance for most non-structural components. Horizontal accelerations are generally lower than predicted from ASCE 41 for regular non-rocking structures. Vertical accelerations in the gravity framing directly connected to the rocking frame are however higher than those predicted for ordinary structures. Vertical ground motions have limited effect on frame response.
\end{abstract}

Keywords: Braced steel frames; Retrofit; Rocking; Column uplift; Column impact; Energy dissipation; Floor accelerations

\section{Introduction}

Over the past half century, seismic design and detailing requirements for building structures have considerably evolved worldwide. For most building structures in Canada, seismic loads specified in the National Building Code of Canada (NBCC) have steadily increased during this period of time [1-4]. For steel structures, ductile seismic detailing requirements and capacity design provisions were introduced in 1989 in the steel design standard CSA S16 and have been continually updated since $[5,6]$. As a result, steel building structures designed prior to the 1990 s generally do not meet current specifications and standards; hence, seismic retrofit may be needed to offer a sufficient level of safety to occupants. The need for seismic upgrade has also become a major issue in seismically active regions in view of the social and economic consequences resulting from damage to building structures and their contents that have been observed after recent (2010-11) earthquakes in Tohoku, Japan, and Christchurch, New Zealand.

Building owners seek earthquake retrofit solutions that can provide the required safety level and reduce to a minimum the repair costs and downtime after a major seismic event. One such solution is the steel rocking braced frame (RBF) system in which columns of the existing braced frames are allowed to uplift during strong earthquake ground motions. Forces and deformations in the structures are reduced due to the resulting uncoupling in base overturning moments. The rocking response and horizontal deflections can be controlled by adding vertical posttensioned tendons (PT) to provide self-centring capacity to the system. The rocking frame exists in two configurations: one where the frame is part of the gravity system, and hence benefits from the contributions of gravity loads to self-centring; a second, where the frame is decoupled from the gravity system to prevent its vertical 
response and possible damage resulting from column impact upon rocking. Energy dissipative (ED) devices may also be inserted at the column bases, between rocking and non-rocking portions of the structure, or between two adjacent rocking frames to further control column uplift and lateral drifts. The system is generally designed so that the structure returns to its original position with no or minimal damage after a severe earthquake. The response of steel RBFs with various ED systems has been investigated in several past experimental programs [7-15] and numerical simulations [16-17]. The system has been implemented in several new structures, including a 2-storey building in California [18] and in buildings ranging from 4 to 15 storeys in New Zealand [19-20]. Of these, the 15storey building in New Zealand has successfully withstood medium size earthquakes. Guidelines have been proposed for the design of RBFs [21-24]. Most of the research and implementations to date have been realized on RBFs with PT elements in a configuration where the RBF is decoupled from the gravity load carrying system.

For seismic retrofit, a rocking steel braced frame can represent an effective solution because braced frames may already be present in the deficient structure, column bases can be easily disconnected from foundations and member forces can be reduced below the capacity of the members so that the original structure can be kept with only minor modifications. Rocking frames also impose limited overturning moment at their bases, thereby minimizing alterations to the existing foundations. For low-rise buildings, the system is even more attractive because higher mode response is limited in these structures, contrary to taller frames where these effects can be more pronounced and pose a challenge for implementation of a rocking system. Furthermore, given that the overturning moments are small, the gravity loads supported by the rocking frame may provide sufficient self-centring capacity to satisfy the target lateral response objectives, as shown in $[9,16]$. Post-tensioning would not be needed, which would further reduce retrofit costs. In addition, the use of PT in low-rise buildings poses a challenge to accommodate the expected strain demand [18]. Relying on gravity to control rocking however implies uplift displacements of the floors connected to the rocking frame, which may have detrimental consequences such as high column loads as well as additional moments and shears caused by vertical accelerations induced by column impacts, as reported in [e.g., $7,8,10]$. In [24], engineers are warned that column impact effects must be considered when floors are connected to the rocking frame but no specific design provisions are given to address the issue. There was therefore a need to study these effects on the integrity and response of the gravity load system, and as such the study presented herein was warranted.

This article presents a numerical study that was performed to evaluate the possibility of transforming seismically deficient steel braced frames in existing low-rise buildings into rocking braced frames to reduce seismic retrofit costs and achieve superior seismic performance. Re-centring response is intended to be achieved by gravity loads supported by the rocking frames alone. Friction based ED devices are used to control drifts. The structures studied are fictitious 2- and 3-storey steel buildings designed in the early 1980s. They are assumed to be located in two regions of Canada exhibiting different seismic conditions; furthermore, two different local soil conditions are considered at each location to examine the possible influence of ground motion amplitude and signature on rocking response. In the article, the existing structures are first evaluated according to the current building code [25] and the ASCE 41-13 Standard [26]. The potential of the RBF retrofit solution is then evaluated from the study of the static equilibrium of the frames upon rocking. The study also provides criteria for selecting the activation load of the ED systems. Final ED capacities are determined to minimize force demands on the structure and foundations while minimizing lateral displacements in preliminary nonlinear dynamic analyses. The performance of the RBF retrofit solution is verified through nonlinear response history analysis and using the acceptance criteria of the ASCE 41-13 Standard. Possible effects of higher mode response and column impact on member forces and floor accelerations are investigated. The analyses are performed using the commercially available computer software SAP2000 [27], as would typically be done in day-to-day practice. The influence of vertical ground motions is also studied and alternative ED systems with ring springs and bars yielding in tension are examined. Although the study is performed in the context of seismic retrofit, the findings can also be used for the application of gravity rocking steel braced frames for new structures. 


\section{Seismic design and evaluation of the prototype structures}

The structures studied are hypothetical commercial 2- and 3-storey buildings of normal importance designed in accordance with the $1980 \mathrm{NBCC}$ [28] and the CSA S16.1-M78 steel standard [29], i.e. prior to the implementation of modern seismic design provisions. The buildings are assumed to be located in Vancouver, British Columbia, on the Pacific west coast, and Montreal, Quebec, in eastern Canada. The former site is exposed to earthquakes from three main seismic sources (subduction interplate earthquakes, deep in-slab earthquakes, and intraplate crustal earthquakes) similar to cities such as Seattle and Portland in the North Western U.S. Montreal is a region of low to moderate seismicity in eastern North America, in this case similar to Boston and New York in the U.S. Seismic ground motions in this region are expected to be richer in high frequencies compared to those along the west coast [28]. To further investigate the possible effects of ground motion characteristics on frame rocking, site classes $\mathrm{C}$ (soft rock and firm ground) and E (soft soils) were studied for each location.

As shown in Figure 1, two building sizes were chosen for the two sites; the dimensions were chosen to obtain the same seismic design loads for the two cases. In the 1980 NBCC the seismic loads for Vancouver were twice the values specified for Montreal; as such, two braced frames along each exterior wall were used for the structures in Vancouver. Hence, for each building height, the same braced frame design could be used for all four cases. The structural response was studied in the N-S direction and chevron bracing was selected because this simple and effective configuration was commonly used before the 1990s. Light roof and floor framing systems with $38 \mathrm{~mm}$ steel deck panels placed on open web steel joists (OWSJs) supported on W-shape girders were also adopted to reflect past practice. At floor levels, a $63 \mathrm{~mm}$ thick concrete composite slab was used. The resulting dead loads are given in Figure 1. Such light systems, combined with the fact that the braced frames are located on the exterior walls, represented a lower bound (critical) condition in terms of gravity loads available to control rocking response.

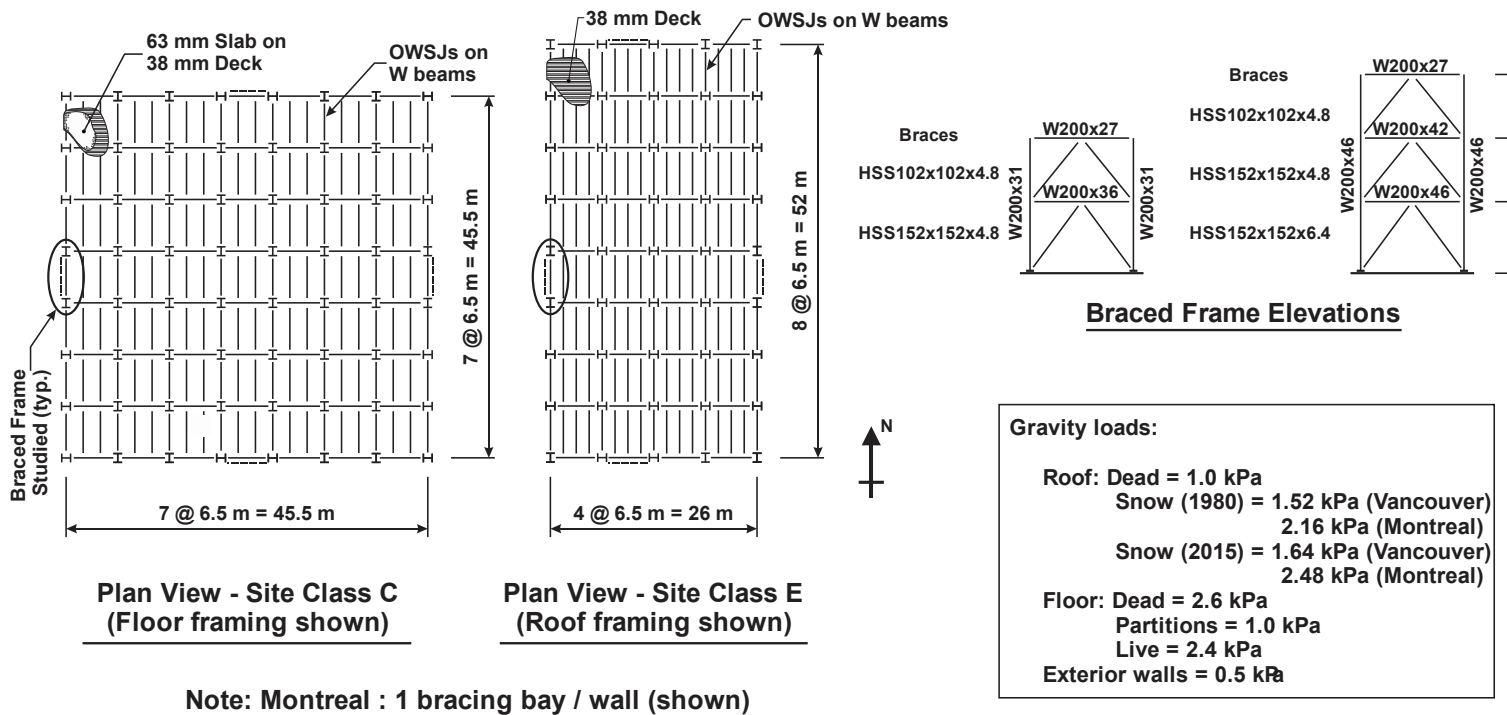
Vancouver: 2 bracing bays / wall

Figure 1. Studied Buildings: Plan view, braced frame elevations and design gravity loads.

\subsection{Original (1980) Design}

In the $1980 \mathrm{NBCC}$, the design base shear $V$ was given by:

$$
V_{1980}=A S K I F W
$$

where $A$ is the peak ground acceleration at the site ( $0.08 \mathrm{~g}$ in Vancouver, $0.04 \mathrm{~g}$ in Montreal), $S$ is the seismic coefficient, $K$ reflects the ductility of the seismic force resisting system ( $=1.0$ for steel chevron bracing) $I$ is the importance factor ( $=1.0$ for buildings of the normal importance), $F$ is the foundation factor ( $=1.0$ and 1.5 , for firm ground and soft soil conditions, respectively), and $W$ is the seismic weight (dead load plus $25 \%$ roof snow load). Design roof snow loads in the 1980 NBCC are given in Fig. 1. The seismic coefficient $S$ was given by:

$$
S=\frac{0.5}{\sqrt{T}} \leq 1.0 \quad \text {, with } T=\frac{0.09 h_{\mathrm{n}}}{\sqrt{D}}
$$


where $T$ is the building period, $h_{\mathrm{n}}$ is the building height $(8.5 \mathrm{~m}$ and $12.5 \mathrm{~m}$, respectively, for the 2- and 3-storey buildings) and $D$ is the length of the building in the N-S direction ( $45 \mathrm{~m}$ and $52 \mathrm{~m}$ for site classes $\mathrm{C}$ and $\mathrm{E}$, respectively).

Base shear calculations are summarized in Table 1. In this article, the different cases are designated using the location, site condition, and number of storeys (e.g., MC2 = 2-storey building on site class C in Montreal). As shown, building periods are such that $S=1.0$ in all cases. Note that the 1980 NBCC permitted to limit the product $F \cdot S$ to 1.0 for such short-period structures, but this possible relaxation was not considered herein, which resulted in the two different building sizes shown in Figure 1 . The base shears per braced frame ( $\left.V_{1980} / \mathrm{BF}\right)$ are given in Table 1 . For simplicity, accidental torsion was omitted in this study and the values given are equal to the total base shear divided by the number of braced frames acting in the N-S direction. As shown, due to differences in roof snow loads between Vancouver and Montreal, base shears slightly vary for a given building height, but the differences are small and the same braced frame design was obtained for all frames of a given height. In the 1980 NBCC two seismic load combinations had to be considered: $1.25 \mathrm{D}+1.5 \mathrm{Q}$ and $1.25 \mathrm{D}+0.7(1.5 \mathrm{~L}+1.5 \mathrm{Q})$, where $\mathrm{D}, \mathrm{L}$, and $\mathrm{Q}$ were respectively the dead load, the live load including snow, and the earthquake load. The first combination controlled the braced frame design for the buildings studied. Further, the members were chosen to minimize steel tonnage. The selected sizes for both braced frame heights are given in Figure 1. The braces are square cold-formed HSS made of CSA G40.20/21-350W steel ( $\left.F_{\mathrm{y}}=350 \mathrm{MPa}\right)$, whereas the beams and columns are hot-rolled W-shapes with CSA G40-300W steel $\left(F_{\mathrm{y}}=300 \mathrm{MPa}\right)$, reflecting the practice in the 1980s [29].

Table 1 Base shear calculations (1980 \& 2015 NBCC) and computed periods

\begin{tabular}{|c|c|c|c|c|c|c|c|c|}
\hline Case & $\mathrm{M} 2 \mathrm{C}$ & $\mathrm{M} 3 \mathrm{C}$ & M2E & M3E & $\mathrm{V} 2 \mathrm{C}$ & $\mathrm{V} 3 \mathrm{C}$ & V2E & V3E \\
\hline \multicolumn{9}{|c|}{ Base shear calculations according to $1980 \mathrm{NBCC}(K=I=1.0)$} \\
\hline$A$ & 0.04 & 0.04 & 0.04 & 0.04 & 0.08 & 0.08 & 0.08 & 0.08 \\
\hline$T(\mathrm{~s})$ & 0.11 & 0.17 & 0.11 & 0.16 & 0.11 & 0.17 & 0.11 & 0.16 \\
\hline$S$ & 1.0 & 1.0 & 1.0 & 1.0 & 1.0 & 1.0 & 1.0 & 1.0 \\
\hline$F$ & 1.0 & 1.0 & 1.5 & 1.5 & 1.0 & 1.0 & 1.5 & 1.5 \\
\hline$W(\mathrm{kN})$ & 11210 & 19027 & 7437 & 12616 & 10879 & 18695 & 7220 & 12400 \\
\hline$V_{1980} / \mathrm{BF}(\mathrm{kN})$ & 224 & 381 & 223 & 378 & 218 & 374 & 217 & 372 \\
\hline \multicolumn{9}{|c|}{ Computed periods of vibration } \\
\hline$T_{1}(\mathrm{~s})$ & 0.623 & 0.865 & 0.508 & 0.705 & 0.423 & 0.594 & 0.345 & 0.484 \\
\hline$T_{2}(\mathrm{~s})$ & 0.297 & 0.360 & 0.242 & 0.294 & 0.205 & 0.248 & 0.167 & 0.202 \\
\hline$T_{3}(\mathrm{~s})$ & - & 0.243 & - & 0.198 & - & 0.171 & - & 0.139 \\
\hline \multicolumn{9}{|c|}{ Base shear calculations according to $2015 N B C C\left(M_{\mathrm{V}}=I_{\mathrm{E}}=1.0 ; R_{\mathrm{d}}=1.5 ; R_{\mathrm{o}}=1.3\right)$} \\
\hline$T_{\mathrm{a}}(\mathrm{s})$ & 0.425 & 0.625 & 0.425 & 0.625 & 0.415 & 0.580 & 0.337 & 0.470 \\
\hline$S\left(T_{\mathrm{a}}\right)$ & 0.381 & 0.270 & 0.499 & 0.408 & 0.778 & 0.699 & 1.022 & 1.022 \\
\hline$W(\mathrm{kN})$ & 10340 & 17122 & 6869 & 11372 & 9906 & 16687 & 6585 & 11088 \\
\hline$V_{\mathrm{ed}} / \mathrm{BF}(\mathrm{kN})$ & 1305 & 1482 & 1449 & 1856 & 1795 & 2491 & 1572 & 2438 \\
\hline$V_{2015} / \mathrm{BF}(\mathrm{kN})$ & 1010 & 1183 & 806 & 1189 & 955 & 1477 & 863 & 1453 \\
\hline$V_{\mathrm{d}} / \mathrm{BF}(\mathrm{kN})$ & $808^{1}$ & $946^{1}$ & 743 & 952 & 892 & 1278 & 806 & 1250 \\
\hline$V_{\mathrm{d}} / 1.5 V_{1980}$ & 2.40 & 1.66 & 2.22 & 1.68 & 2.73 & 2.28 & 2.48 & 2.24 \\
\hline
\end{tabular}

${ }^{1} V_{\mathrm{d}}$ controlled by lower limit $0.8 V_{2015}$

\subsection{Seismic evaluation using $2015 \mathrm{NBCC}$}

A natural first step in the seismic retrofit process is to verify the adequacy of the system with respect to the current codes. The braced frames are therefore verified against the provisions of the 2015 NBCC and the CSA S16-14 Steel 
Design Standard [30]. Dynamic response spectrum analysis (RSA) is used to obtain a better assessment of the seismic demand. In the 2015 NBCC, RSA is performed using the design spectrum $S$ obtained from site specific uniform hazard spectral ordinates $S_{\mathrm{a}}$ specified at periods of $0.2,0.5,1.0,2.0,5.0$ and $10.0 \mathrm{~s}$ for a probability of exceedance of $2 \%$ in 50 years. The values of $S_{\mathrm{a}}$ are modified using site coefficients $F$ that depend on the local soil conditions and peak ground accelerations. Values of $S$ for site classes $\mathrm{C}$ and $\mathrm{E}$ at both locations are plotted in Figure 2. When using RSA for regular structures, as those studied here, the design base shear $V_{\mathrm{d}}$ is the larger of $V_{\mathrm{ed}}\left(I_{\mathrm{E}} / R_{\mathrm{d}} R_{\mathrm{o}}\right)$ and $0.8 V_{2015}$ where $V_{\text {ed }}$ is the design elastic base shear from RSA and $V_{2015}$ is the static design base shear:

$$
V_{2015}=\frac{S\left(T_{\mathrm{a}}\right) \mathrm{I}_{\mathrm{E}} M_{\mathrm{V}} W}{R_{\mathrm{d}} R_{\mathrm{O}}}
$$

In this expression, $S$ is the design spectrum, as defined above, $T_{\mathrm{a}}$ is the fundamental period of vibration for design, $I_{\mathrm{E}}$ is the importance factor (= 1.0 for the structures studied), $M_{\mathrm{V}}$ is a factor that accounts for higher mode effects on base shear (= 1.0 for low-rise braced frames as those considered herein), $W$ is the seismic weight, and $R_{\mathrm{d}}$ and $R_{\mathrm{o}}$ are the ductility- and overstrength-related force modification factors. In the $2015 \mathrm{NBCC}$, the period $T_{\mathrm{a}}$ for braced frames must be determined from the empirical expression $T_{\mathrm{a}}=0.025 h_{\mathrm{n}}$. Alternatively, $T_{\mathrm{a}}$ can be taken equal to the fundamental period $T_{1}$ from dynamic analysis without exceeding twice the empirical value, i.e. 0.425 and $0.625 \mathrm{~s}$ for the 2- and 3storey frames, respectively. The seismic weight is the same as in the 1980 NBCC except that the partition wall load can be reduced from 1.0 to $0.5 \mathrm{kPa}$ when determining $W$. Further, as shown in Figure 1, the roof snow loads at both locations have increased between 1980 and 2015, which also affected $W$. Since the braced frames as designed do not include any special detailing to enhance seismic ductility, they were considered as of the 2015 NBCC Conventional Construction (Type CC) category, for which $R_{\mathrm{d}}=1.5$ and $R_{\mathrm{o}}=1.3$. In the $2015 \mathrm{NBCC}$, values of $V_{\mathrm{ed}}$ and $V_{2015}$ from Equation 3 need not exceed the larger of $2 / 3$ the value determined with $T_{\mathrm{a}}=0.2 \mathrm{~s}$ and the value determined with $T_{\mathrm{a}}=$ $0.5 \mathrm{~s}$. These upper limits were considered herein. Once $V_{\mathrm{d}}$ is determined, the RSA results are multiplied by $V_{\mathrm{d}} / V_{\mathrm{ed}}$

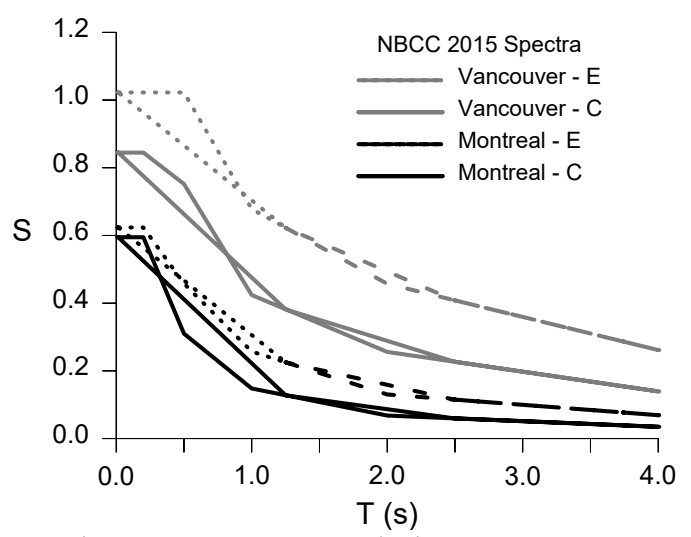

Figure 22015 NBCC design spectra [27]

The periods of the structures in all their lateral modes, as computed from dynamic analysis using the seismic weights as per the 2015 NBCC, are given in Table 1. Details of the calculations of $V_{2015}$ are also presented in the table. As shown, the upper limit on $T_{\mathrm{a}}$ controlled for all cases in Montreal, whereas $T_{1}$ was used for the structures in Vancouver. Base shears $V_{2015}$ and $V_{\mathrm{d}}$ are given per braced frame and, as shown, $0.8 V_{2015}$ governed $V_{\mathrm{d}}$ only for the structures on site $\mathrm{C}$ in Montreal. For other cases, $V_{\mathrm{d}}$ was determined using $V_{\text {ed }}$ from the RSA. In the $2015 \mathrm{NBCC}$, the load combination including seismic effects is $1.0 \mathrm{D}+0.5 \mathrm{~L}+0.25 \mathrm{~S}+1.0 \mathrm{E}$, where $\mathrm{S}$ is the roof snow load and $\mathrm{E}$ represents the seismic loads. For comparison with the 1980 seismic loads, the ratio $V_{\mathrm{d}} / 1.5 V_{1980}$ is therefore used in Table 1 to account for the different seismic load factors. The ratio varies between 1.66 and 2.73 for the 8 cases, reflecting the various changes in code provisions between 1980 and 2015 depending on location, site conditions and building periods. The lowest values (1.66 and 1.68) are obtained for the 3-storey building in Montreal, whereas the highest ratios (2.48 and 2.73) are for the two-storey frames in Vancouver. Site class has no significant influence; however, for class E sites, the ratios would be 1.5 times higher had the upper limit $F: S=1.0$ been considered in the original design. These results indicate that a major retrofit would be needed to meet the strength requirements prescribed in the 2015 NBCC.

\subsection{Seismic evaluation of existing buildings according to ASCE 41}

The ASCE 41-13 Standard contains a comprehensive procedure for the evaluation and rehabilitation of seismically deficient building structures. In this standard, a performance objective must be defined in terms of performance and 
hazard levels, as illustrated in Table 2. Basic performance levels for existing buildings (BPOE) are Life Safety under a seismic hazard having a probability of exceedance of $20 \%$ in 50 years (case g) or Collapse Prevention under $5 \%$ in 50 years earthquakes (case 1). Enhanced performance objectives may also be proposed, such as Immediate Occupancy for $\mathrm{MCE}_{\mathrm{R}}$ hazard (case n). ASCE 41 is also used for the evaluation and rehabilitation of non-structural components. An evaluation and retrofit scheme is then defined using a letter-number combination; the numbers ( 1 to 6$)$ and the letters (A to D) respectively representing the level of retrofit for structural and non-structural components (Table 3). Among the 24 possible combinations, pairs 1-A, 1-B, 3-C, and 5-D are the most commonly adopted.

Table 2 Performance objectives - From ASCE 41-13 Table C2-2 [26]

\begin{tabular}{ccccc}
\hline $\begin{array}{c}\text { Seismic Hazard } \\
\text { Level }\end{array}$ & $\begin{array}{c}\text { Operational } \\
\text { Performance Level } \\
(1-\mathrm{A})\end{array}$ & $\begin{array}{c}\text { Immediate } \\
\text { Occupancy } \\
\text { Performance Level } \\
(1-\mathrm{B})\end{array}$ & $\begin{array}{c}\text { Life Safety } \\
\text { Performance Level } \\
(3-\mathrm{C})\end{array}$ & $\begin{array}{c}\text { Collapse } \\
\text { Prevention } \\
\text { Performance Level } \\
(5-\mathrm{D})\end{array}$ \\
\hline $\begin{array}{c}50 \% / 50 \text { years } \\
\begin{array}{c}\mathrm{BSE}-1 \mathrm{E}(20 \% / 50 \\
\text { years) }\end{array}\end{array}$ & $\mathrm{a}$ & $\mathrm{b}$ & $\mathrm{c}$ & $\mathrm{d}$ \\
\hline $\begin{array}{c}\text { BSE-2E (5\%/50 } \\
\text { years) }\end{array}$ & $\mathrm{i}$ & $\mathrm{j}$ & $\mathrm{k}$ & $\mathrm{h}$ \\
\hline $\begin{array}{c}\text { BSE-2N (ASCE } 7 \\
\text { MCER) }[31]\end{array}$ & $\mathrm{m}$ & $\mathrm{n}$ & $\mathrm{j}$ & $\mathrm{p}$ \\
\hline
\end{tabular}

Table 3 Target building performance levels - From ASCE 41-13 Table C2-8* [26]

\begin{tabular}{|c|c|c|c|c|c|c|}
\hline \multirow[b]{2}{*}{$\begin{array}{l}\text { Non-Structural } \\
\text { Performance Levels }\end{array}$} & \multicolumn{6}{|c|}{ Structural Performance levels } \\
\hline & $\begin{array}{l}\text { Immediate } \\
\text { Occupancy } \\
\text { (S-1) }\end{array}$ & $\begin{array}{l}\text { Damage } \\
\text { Control } \\
(\mathrm{S}-2)\end{array}$ & $\begin{array}{l}\text { Life } \\
\text { Safety } \\
\text { (S-3) }\end{array}$ & $\begin{array}{l}\text { Limited } \\
\text { Safety } \\
\text { (S-4) }\end{array}$ & $\begin{array}{l}\text { Collapse } \\
\text { Prevention } \\
\text { (S-5) }\end{array}$ & $\begin{array}{l}\text { Not } \\
\text { Considered } \\
(\mathrm{S}-6)\end{array}$ \\
\hline $\begin{array}{l}\text { Operational } \\
(\mathrm{N}-\mathrm{A})\end{array}$ & Operational 1-A & $2-\mathrm{A}$ & NR & NR & NR & NR \\
\hline $\begin{array}{l}\text { Position Retention (N- } \\
\text { B) }\end{array}$ & $\begin{array}{l}\text { Immediate } \\
\text { Occupancy 1-B }\end{array}$ & $2-B$ & $3-B$ & $4-B$ & NR & NR \\
\hline $\begin{array}{l}\text { Life Safety } \\
\text { (N-C) }\end{array}$ & $1-\mathrm{C}$ & $2-\mathrm{C}$ & $\begin{array}{l}\text { Life } \\
\text { Safety }\end{array}$ & $4-C$ & $5-\mathrm{C}$ & $6-\mathrm{C}$ \\
\hline $\begin{array}{l}\text { Not Considered } \\
\text { (N-D) }\end{array}$ & NR & NR & $3-D$ & 4-D & $\begin{array}{l}\text { Collapse } \\
\text { Prevention 5- } \\
\text { D }\end{array}$ & $\begin{array}{l}\text { No evaluation } \\
\text { or retrofit }\end{array}$ \\
\hline
\end{tabular}

$* N R=$ Not recommended

To confirm the need for retrofit, as was identified using the provisions of the 2015 NBCC, a limited structural evaluation using the ASCE 41 linear dynamic procedure is performed herein on the main structural components of the braced frames. For the evaluation of deformation-controlled (ductile) actions such as the braces, the acceptance criteria is given by:

$$
m \kappa Q_{C E} \geq Q_{U D}
$$

In this expression, $m$ is a ductility factor that reflects the permissible ductility of the components, which depends on the component properties and the performance level, $\kappa$ is the knowledge factor, $Q_{\mathrm{CE}}$ is the component expected strength, and $Q_{\mathrm{UD}}$ is the applied force. For the braces, $\kappa$ is taken equal to 1.0, $Q_{\mathrm{CE}}$ is calculated using CSA S16-14 with the resistance factor $\phi=1.0$, an effective length of $0.9 \mathrm{~L}$ is assumed, the expected yield strength is defined as $R_{\mathrm{y}} F_{\mathrm{y}}$, and $Q_{\mathrm{UD}}$ is as obtained from a response spectrum analysis performed using the spectra from the 2015 NBCC. The ratios $Q_{U D} / \kappa Q_{C E}$ are determined and are compared to permissible $m$ factors to establish the performance level 
that can be achieved with the structure in its existing condition. Values of $\kappa Q_{C E}$ and $Q_{U D} / \kappa Q_{C E}$ are given in Table 4 for the braces at every level of both the 3- and 2-storey buildings at all locations. Values of the permissible $m$ factors for two structural performance levels, as determined as a function of brace slenderness and $b / t$ ratios, are also given in the table. Those values were established for HSS braces under compression, considering the cross-section slenderness and existing connection details. All braces of the buildings meet the criteria for life safety (LS) performance and would not need replacement, which is a markedly more favourable assessment compared to the conclusion obtained when using the $2015 \mathrm{NBCC}$ (braces would need to be strengthened by a factor of approximately 2.0).

Table 4 ASCE 41 evaluation of bracing members.

\begin{tabular}{|c|c|c|c|c|c|c|c|c|c|c|}
\hline \multicolumn{6}{|c|}{ 3-Storey Buildings } & \multicolumn{5}{|c|}{ 2-Storey Buildings } \\
\hline \multirow{2}{*}{$\begin{array}{c}\text { Storey } \\
\text { Level }\end{array}$} & \multirow{2}{*}{$\begin{array}{l}\text { Case } \\
\text { studied }\end{array}$} & \multirow{2}{*}{$\begin{array}{l}\mathrm{k} Q_{\mathrm{CE}} \\
(\mathrm{kN})\end{array}$} & \multirow{2}{*}{$\frac{Q_{U D}}{\kappa Q_{C E}}$} & \multicolumn{2}{|c|}{$m$-factor } & \multirow{2}{*}{$\begin{array}{l}\text { Case } \\
\text { studied }\end{array}$} & \multirow{2}{*}{$\begin{array}{l}\mathrm{K} Q_{\mathrm{CE}} \\
(\mathrm{kN})\end{array}$} & \multirow{2}{*}{$\frac{Q_{U D}}{\kappa Q_{C E}}$} & \multicolumn{2}{|c|}{$\begin{array}{c}m- \\
\text { factor }\end{array}$} \\
\hline & & & & 10 & LS & & & & 10 & LS \\
\hline \multirow{4}{*}{3} & $\mathrm{M} 3 \mathrm{C}$ & \multirow{4}{*}{212} & 2.34 & \multirow{4}{*}{1.0} & \multirow{4}{*}{4.0} & & & & & \\
\hline & M3E & & 2.64 & & & & & & & \\
\hline & V3C & & 3.10 & & & & & & & \\
\hline & V3E & & 2.97 & & & & & & & \\
\hline \multirow{4}{*}{2} & M3C & \multirow{4}{*}{583} & 1.55 & \multirow{4}{*}{1.0} & \multirow{4}{*}{3.77} & $\mathrm{M} 2 \mathrm{C}$ & \multirow{4}{*}{212} & 2.51 & \multirow{4}{*}{1.0} & \multirow{4}{*}{4.00} \\
\hline & M3E & & 1.98 & & & M2E & & 2.71 & & \\
\hline & V3C & & 2.63 & & & V2C & & 3.04 & & \\
\hline & V3E & & 2.59 & & & V2E & & 2.66 & & \\
\hline \multirow{4}{*}{1} & M3C & \multirow{4}{*}{691} & 1.86 & \multirow{4}{*}{1.0} & \multirow{4}{*}{3.90} & $\mathrm{M} 2 \mathrm{C}$ & \multirow{4}{*}{535} & 2.11 & \multirow{4}{*}{1.0} & \multirow{4}{*}{3.88} \\
\hline & M3E & & 2.32 & & & M2E & & 2.34 & & \\
\hline & V3C & & 3.11 & & & V2C & & 3.89 & & \\
\hline & V3E & & 3.04 & & & V2E & & 2.54 & & \\
\hline
\end{tabular}

The same approach is used for the braced frame columns except that columns are considered as force-controlled components for which the acceptance criteria is given by:

$$
\kappa Q_{C L} \geq Q_{U F}
$$

where $Q_{\mathrm{CL}}$ is the lower-bound strength and $Q_{\mathrm{UF}}$ is the applied force from elastic response spectrum analysis. The resistance $Q_{\text {CL }}$ corresponds to the nominal strength, as determined with CSA S16-14. Evaluation results for the columns at the first storey are presented in Table 5. Column strengthening would be needed for all braced frames.

Table 5 ASCE 41 evaluation of the first-storey columns.

\begin{tabular}{cccccc}
\hline \multicolumn{3}{c}{ 3-Storey Buildings } & \multicolumn{3}{c}{ 2-Storey Buildings } \\
\hline \multirow{2}{*}{ Case } & $\begin{array}{c}\mathrm{k} Q_{\mathrm{CL}} \\
(\mathrm{kN})\end{array}$ & $\frac{Q_{U F}}{\kappa Q_{C L}}$ & Case & $\begin{array}{c}\mathrm{kQ} \mathrm{QL}_{\mathrm{cL}} \\
(\mathrm{kN})\end{array}$ & $\frac{Q_{U F}}{\kappa Q_{C L}}$ \\
\hline $\mathrm{M} 3 \mathrm{C}$ & & 2.85 & $\mathrm{M} 2 \mathrm{C}$ & & 4.46 \\
$\mathrm{M} 3 \mathrm{E}$ & 963 & 2.85 & $\mathrm{M} 2 \mathrm{E}$ & 342 & 4.46 \\
$\mathrm{~V} 3 \mathrm{C}$ & & 2.84 & $\mathrm{~V} 2 \mathrm{C}$ & & 4.47 \\
$\mathrm{~V} 3 \mathrm{E}$ & & 2.84 & $\mathrm{~V} 2 \mathrm{E}$ & & 4.47 \\
\hline
\end{tabular}

Beams in chevron bracing must resist the gravity loads together with the axial forces and bending moments that are caused by simultaneous yielding of the tension brace and buckling of the compression brace as the current CSA S16. These actions must also be considered as force-controlled actions, which represents a very severe condition. For instance, the W200x46 beam at the first level of the 3-storey frame (Fig. 1) would have to withstand an axial compression load of $489 \mathrm{kN}$ and a bending moment of $3661 \mathrm{kN}-\mathrm{m}$, which will require increasing the beam size to W1000x272. Similar modifications would be required for the other beams of the two braced frames. Replacement of 
the beams would require significant invasive repair work to the structures, including modifications to the bracing members (brace lengths are changed), to interior finishes, as well as extensive reparation of the façade assuming the alterations will be accomplished from the exterior of the building.

ASCE 41 shows that beams, columns, and likely the braces will still require important strengthening or replacement. Evaluation of member connections is not discussed here, but all connections will also need to be modified to achieve Life Safety performance. The foundation will also likely need to be reinforced to achieve this performance level. Such a retrofit work is expected to require significant investment and impose some disruption to functionality of the building. In addition, all $Q_{U D} / \kappa Q_{C E}$ values for the bracing members exceed the $m$ factor of 1.0 permitted for immediate occupancy (IO) performance, which means that the braces will experience inelastic response in the form of buckling in compression and yielding in tension during a severe earthquake. Additional repair costs and downtime periods should therefore be anticipated in the future for these structures. In this context, it would be wise to consider alternative strategies for the retrofit of the buildings.

\section{Using rocking braced frames (RBF) as a retrofit}

Among the various possible alternative retrofit schemes examined, base rocking appeared suitable for this particular application mainly because seismic induced forces can be kept below or near to the capacity of the existing structure and the retrofit effort can be limited to modifying the structure's base to allow rocking, which eliminates the substantial investment required for strengthening the structure. For this low-rise application, it was also envisioned that gravity alone, coupled with low-capacity supplemental ED devices at column bases, could provide sufficient re-centring capacity and control drift. In addition, with this system, it was expected that the structure would remain nearly intact after a severe earthquake.

The proposed rocking frame system is schematically illustrated in Figure 3a for the 3-storey buildings. The first step consists of removing the nuts from the anchor rods. A strut is added between the base of the columns to transfer the base shear from the brace connected to the uplifted column to the pivot column and prevent flexure of the lifting columns during rocking. Anchor blocks made from I-shaped steel profiles are connected to the foundations on the exterior side of both columns to resist base shear by bearing and prevent sliding of the frame. The concept has been successfully applied in previous research [12-14]. Finally, ED devices mounted on the anchors blocks are fieldconnected to the columns. Friction ED was selected is this study, in view of its simplicity and reliable performance in previous studies [12]. Other ED systems were also examined, as discussed in Section 5.1.

a)

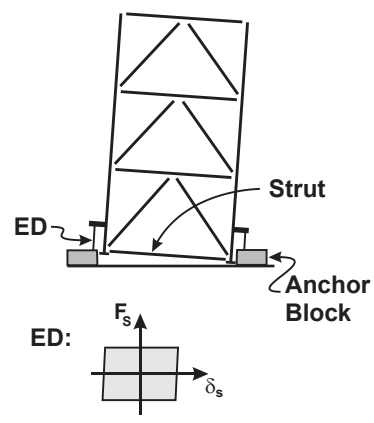

b)

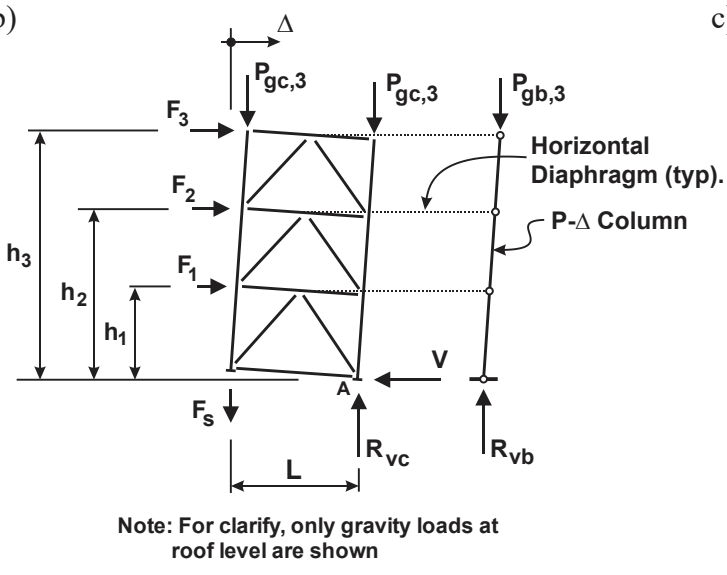

c)

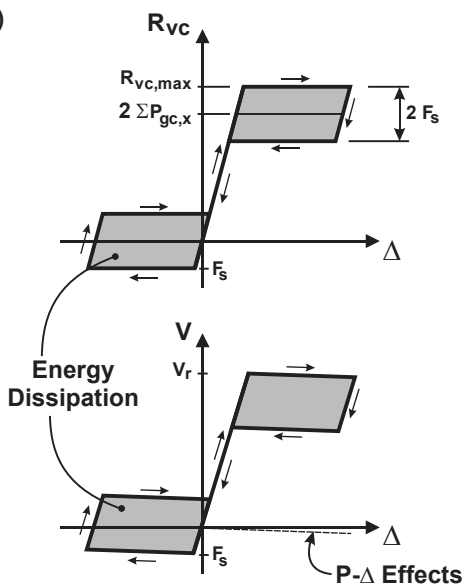

Figure 3 (a) Schematic description of the RBF studied; (b) force equilibrium of the RBF upon rocking; and (c) force versus displacement hysteretic behaviour of the RBF

Preliminary verification of the viability of this rocking retrofit solution and initial selection of the ED devices were done based on the frame rocking response derived from the free-body diagram shown in Figure $3 b$. The frame carries the tributary gravity loads on columns $P_{\text {gc }}$ (only shown at the roof level for clarity) and resists horizontal seismic 
inertia forces $F_{\mathrm{x}}$. The ED devices impose a force $F_{\mathrm{s}}$ resisting to uplift. A $P-\Delta$ column supporting gravity loads $P_{g \mathrm{~b}}$ acting on the rest the building is included. Equilibrium of the vertical forces on the frame gives the maximum anticipated vertical reaction $R_{\mathrm{vc}}$ at the base of the pivot column:

$$
R_{v c, \text { max }}=2 \sum P_{g c, x}+F_{s}
$$

The variation of $R_{\mathrm{vc}}$ during rocking is illustrated in the upper part of Figure $3 \mathrm{c}$. Moment equilibrium gives:

$$
\left(\sum P_{g c, x}+F_{s}\right) L=\sum F_{x} h_{x}+\sum\left(2 P_{g c, x}+P_{g b, x}\right) \Delta_{x}
$$

Assuming a first mode response of the structure, the distribution of the seismic induced forces $F_{\mathrm{x}}$ assumed in the NBCC equivalent static force procedure is adopted:

$$
F_{x}=\frac{W_{x} h_{x}}{\sum\left(W_{x} h_{x}\right)}
$$

Introducing Equation (8) in Equation (7) and assuming that lateral displacements $\Delta_{x}$ upon rocking vary linearly with the building height, the total lateral force $V$ that can be resisted by the RBF is:

$$
V=\frac{\sum W_{x} h_{x}}{\sum\left(W_{x} h_{x}^{2}\right)}\left[\left(\sum P_{g c, x}+F_{s}\right) L-\frac{\Delta_{n}}{h_{n}} \sum\left(2 P_{g c, x}+P_{g b, x}\right) h_{x}\right]
$$

where $\Delta_{n}$ is the displacement at the roof level. Variation of $V$ upon rocking is shown in the lower part of Figure $3 \mathrm{c}$. Neglecting frame elastic deformations, the lateral force $V$ required to trigger rocking, $V_{\mathrm{r}}$, can be estimated by setting $\Delta_{n}$ to zero in Equation (9).

In these above equations, gravity loads are those from the 2015 NBCC load combination with seismic loads described in the previous section $(\mathrm{D}+0.5 \mathrm{~L}+0.25 \mathrm{~S})$. Past studies have shown that drift can be controlled by selecting proper amount of energy dissipation [31-32]. In this study, for each structure, the activation load of the ED devices, $F_{\mathrm{s}}$, was selected to achieve acceptable drift response by trial and error from preliminary response history analyses using selected ground motions. The target drift response is discussed below. In the process, the value of $F_{\mathrm{s}}$ was limited to the following upper limits: $\Sigma P_{\mathrm{gc}, \mathrm{x}}$ so that columns can return to their initial position upon rocking, and the value that would give $R_{\mathrm{vc}, \max }$ from Equation (7) larger than the lower-bound compressive resistance of the existing columns (Table 6). Satisfying the second requirement would also indirectly ensure that the bearing capacity of the existing foundations would not be exceeded. In the selection process, $F_{\mathrm{s}}$ was also kept as low as possible to minimize the lateral force $V$, and thereby the member forces, and reduce uplift and horizontal forces to be resisted by the anchor blocks. Final values of $F_{\mathrm{s}}$ are given in Table 6, together with the values of $\Sigma P_{\mathrm{gc}, \mathrm{x}}$ and the resulting values of $R_{\mathrm{vc}, \max }$ and $V_{\mathrm{r} \text {. As }}$ shown, the limit imposed by $R_{\mathrm{vc} \text {, max }}$ could be satisfied in all cases except for cases M2E, V2C, and V2E for which $R_{\mathrm{vc}, \max }$ slightly exceeds the column strength $Q_{\mathrm{CL}}=342 \mathrm{kN}$. For these three cases, $F_{\mathrm{s}}$ would need to be adjusted in a final design stage, at the expense of augmented drift demand. For this study, it was deemed unnecessary to apply this correction because the objective was to examine the potential of the rocking system. For structures V2E and V3E, values of $F_{\mathrm{s}}$ greater than $\Sigma P_{\mathrm{gc}, \mathrm{x}}$ were also selected to limit drifts. As will be shown, for these two buildings, the analysis results discussed in the next section demonstrated that full-re-centring response could still be obtained despite the high $F_{\text {s value. }}$

Table 6 Properties of the rocking frames (values per braced frame).

\begin{tabular}{lllllllll}
\hline Case & M2C & M3C & M2E & M3E & V2C & V3C & V2E & V3E \\
\hline$\Sigma P_{\mathrm{gcc} \text { x }}(\mathrm{kN})$ & 138 & 257 & 138 & 257 & 133 & 253 & 133 & 253 \\
\hline$F_{\mathrm{s}}(\mathrm{kN})$ & 50 & 100 & 100 & 150 & 100 & 220 & 150 & 300 \\
\hline$R_{\mathrm{vc}, \max }(\mathrm{kN})$ & 326 & 614 & 376 & 664 & 366 & 726 & 416 & 806 \\
\hline$V_{\mathrm{r}}(\mathrm{kN})$ & 190 & 262 & 241 & 300 & 241 & 354 & 354 & 415 \\
\hline$V_{\mathrm{r}} / V_{\mathrm{e}}(\%)$ & 15 & 18 & 17 & 16 & 13 & 14 & 19 & 17 \\
\hline$V_{\mathrm{CE}, \text { braces }}(\mathrm{kN})$ & 588 & 771 & 588 & 771 & 588 & 771 & 588 & 771 \\
\hline$V_{\mathrm{r}} / V_{\mathrm{CE}, \text { braces }}(\%)$ & 32 & 34 & 41 & 39 & 41 & 33 & 50 & 54 \\
\hline
\end{tabular}


In Table 6, the computed values of $V_{\mathrm{r}}$ are compared to the elastic base shears $V_{\mathrm{e}}$ from response spectrum analyses (Table 1). The ratios vary between 13 to $18 \%$, which correspond to force modification factors ranging between 5.6 to 7.7. Such values appeared acceptable for this system based on previous studies for short period structures [15,21]. In the table, the value of $V_{\mathrm{CE}, \text { braces }}$ corresponds to the storey shear that can be resisted by the existing braces at the firststorey of the buildings, based on the brace expected compressive strengths (Table 4). Values of $V_{\mathrm{r}} / V_{\mathrm{CE} \text {,braces }}$ lie between 32 and $54 \%$, indicating that braces in the rocking frames as designed could potentially remain undamaged after a severe seismic event, depending on the severity of the additional demand from higher mode response and column impact. Achieving elastic brace response is of particular importance for chevron braced frames because the beams would not be exposed to the critical unbalanced brace loading case described earlier.

On the basis of these preliminary calculations, it was anticipated that the proposed rocking retrofit solution could lead to ASCE 41 structural performance level Immediate Occupancy under the $2 \%$ in 50 years hazard, which is a much higher level compared to the Life Safety performance objective targeted for new buildings by the 2015 NBCC. Preliminary calculations performed to set the ED activation loads also showed that the storey drifts would remain below $2 \%$ of the storey height under that hazard level, which corresponds to the drift limit specified for most nonstructural components for Position Retention non-structural performance level in ASCE 41. For this performance level, however, floor acceleration limits also apply. If those were verified, the target performance objectives for the structure could be set as Immediate Occupancy (1-B), corresponding to case $\mathrm{n}$ in Table 2. Results of the nonlinear response history analyses performed to confirm this hypothesis are presented in Section 4.

\section{Seismic response of the proposed RBF retrofit solution}

\subsection{Numerical Model and Ground Motions}

Evaluation of the proposed rocking solution was performed using the ASCE 41 nonlinear dynamic procedure. In the numerical model, only the frame nonlinear rocking response is explicitly accounted for as all framing members are expected to remain elastic. Hence, frame members are reproduced using elastic beam elements. This modelling approach was also selected because it allows one to determine by how much the force demands may exceed member capacities, which is useful information to assess the needs for local strengthening, if any. As shown in Figure 4, a 3D model was used in the analysis to include the vertical response of the adjacent gravity load carrying system affected by frame rocking. The gravity system model includes the steel joists and beams at floor and roof levels. Floor slabs are not included as a non-composite floor system was used in the existing structures. The model included a $P-\Delta$ column to include the effects on the response from gravity loads supported by the rest of the building. All gravity loads were specified in the form of vertical masses assigned to the beams and joists so that vertical inertia forces developing upon rocking can be also included.

The analyses were conducted with the commercially available computer software SAP2000. Rocking interfaces were simulated using gap elements (non-linear link representing compression-only link). The friction ED devices were modelled using multi-linear plastic link elements with rigid-plastic behaviour. Rayleigh damping corresponding to $3 \%$ of critical in the first two lateral modes of the fixed based structure was specified. Mass proportional damping was assigned to all nodes whereas stiffness proportional damping was assigned only to the framing members. To avoid unrealistic, excessive numerical damping, no damping was assigned to the gap and link elements used at the column bases. Nonlinear direct integration analysis was performed, including P- $\Delta$ effects. The HHT- $\alpha$ integration scheme [33], with $\alpha=-0.05$, was used to achieve efficiency and numerical stability [34].

The structures were subjected to an ensemble of representative site-specific seismic horizontal ground motion time histories. Selection and scaling of the ground motions was performed in accordance with the provisions of the NBCC 2015 [35;36]. For each location, the selection reflected the magnitude-distance scenarios dominating the seismic hazard in the period range of the structures studied. Separate ensembles were developed for each site condition. For Montreal, the ensembles consisted of two suites of simulated ground motion time histories; 5 motions from M6.0 events and 6 motions from M7.0 events. For Vancouver, the ensembles contained 3 suites of 11 records, each suite being associated with the three sources of earthquakes (shallow crustal, subduction intra-slab, and subduction interface earthquakes) contributing to the hazard in south west British Columbia. All ground motions were scaled to match the design spectra of the 2015 NBCC (Figure 2). As specified in [36], for each location, mean response values were determined for each suite of records and the largest mean value from all suites was retained to represent the seismic 
demand. In Section 4, standard deviations of the results for the most critical suite of records are also presented to illustrate the scatter in the structure response. In all analyses, a constant vertical acceleration of $1.0 \mathrm{~g}$ was applied concomitantly with the horizontal ground motion histories to simulate gravity. This vertical acceleration was gradually applied over a period of $4.5 \mathrm{~s}$ followed by a $0.5 \mathrm{~s}$ pause before the beginning of the seismic motion to avoid inducing vertical oscillations. In some of analyses, the vertical component of the ground motion was also applied to investigate the effects of vertical motions on rocking response. These additional analyses are discussed in Section 5.

Prior to performing response history analyses, modal properties of the fixed base structures were evaluated. The periods of the structures in the lateral modes are given in Table 1. The period in the first vertical vibration mode of the floors is $0.29 \mathrm{~s}$. For the roof, the first vertical mode periods are $0.30 \mathrm{~s}$ in Montreal and $0.27 \mathrm{~s}$ in Vancouver, the difference being due to the different roof snow loads at the two locations. Figure $4 \mathrm{~b}$ shows the first vertical vibration mode of the floors for one three-storey structure.
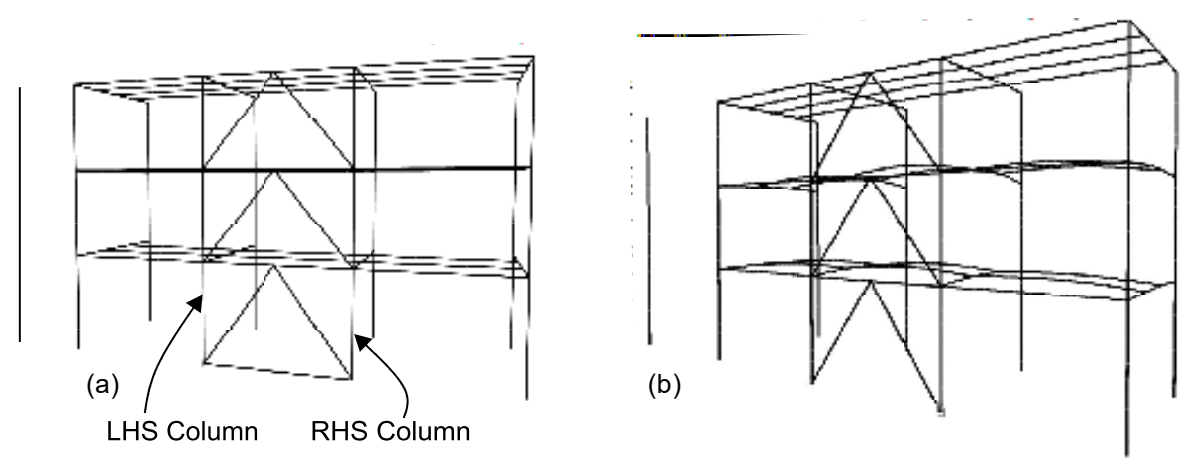

Figure 4 RBF numerical model of the 3-storey building: (a) 3D model with adjacent gravity frame and P- $\Delta$ column; (b) First vertical vibration mode of the floors (site C, Vancouver).

\subsection{Global RBF response}

The response history of key parameters is plotted in Figure 5 for the $\mathrm{M} 3 \mathrm{C}$ building configuration under a M7.0 ground motion. To ease readability, the response is plotted only for $12 \mathrm{~s}$ duration of the strong motion portion of the signal. The force versus drift ratio hysteretic response for the vertical reaction and base shear are also presented in the figure. As shown, the RBF columns alternatively lift off of the foundations under the ground motion; further, the roof lateral displacement $\Delta_{\mathrm{n}}$ is essentially caused by this uplift. For this 3-storey frame, the peak $60 \mathrm{~mm}$ uplift for the column translates into $\Delta_{\mathrm{n}}=0.94 \% h_{\mathrm{n}}(\approx 60 / 6500)$. Small amplitude oscillations in the uplift and roof displacement responses are caused by vibrations in higher modes, as will be described later. As shown, the frame returned to its original position at the end of the strong ground shaking, without residual deformations. That response was observed in all frames, even frames V2E and V3E for which $F_{\mathrm{s}}$ exceeded the column gravity load.

In Figure 5, the base reactions $R_{\mathrm{vc}}$ in compression approach $R_{\mathrm{vc}, \max }$ computed with Equation $6(614 \mathrm{kN})$ when the columns are in contact with the foundation. As expected, $R_{\mathrm{vc}}$ becomes equal to the ED force $F_{\mathrm{s}}(100 \mathrm{kN})$ in tension during column uplift. The hysteresis of the column vertical reactions (upper-right corner in Figure 5) is therefore similar to that assumed in design (upper part of Figure 3c), except that $R_{\mathrm{vc}}$ in compression slightly exceeds $R_{\mathrm{vc}, \max }$ at small deformations. This behaviour is observed just after the columns impact the foundation, as can be seen by the short duration peaks in the $R_{\mathrm{vc}}$ histories. Details of the column response for the same building and ground motion are illustrated in Figure 6. Uplift of the column occurs between 9.7 and $12.1 \mathrm{~s}$. When lifting up, $R_{\mathrm{vc}}$ at the base of this column is equal to $100 \mathrm{kN}$ in tension. The direction of that force is inverted as friction now opposes the column's downward movement for $t>10.7 \mathrm{~s}$. When contact occurs at $12.1 \mathrm{~s}, R_{\mathrm{vc}}$ quickly reaches and slightly exceeds $R_{\mathrm{vc}, \max }$ as the RHS column is lifted up. Between $t=12.7$ and $13 \mathrm{~s}, R_{\mathrm{vc}}$ reduces by $200 \mathrm{kN}\left(2 F_{\mathrm{s}}\right)$ when the vertical movement of the column base is reversed and the column moves downward. 

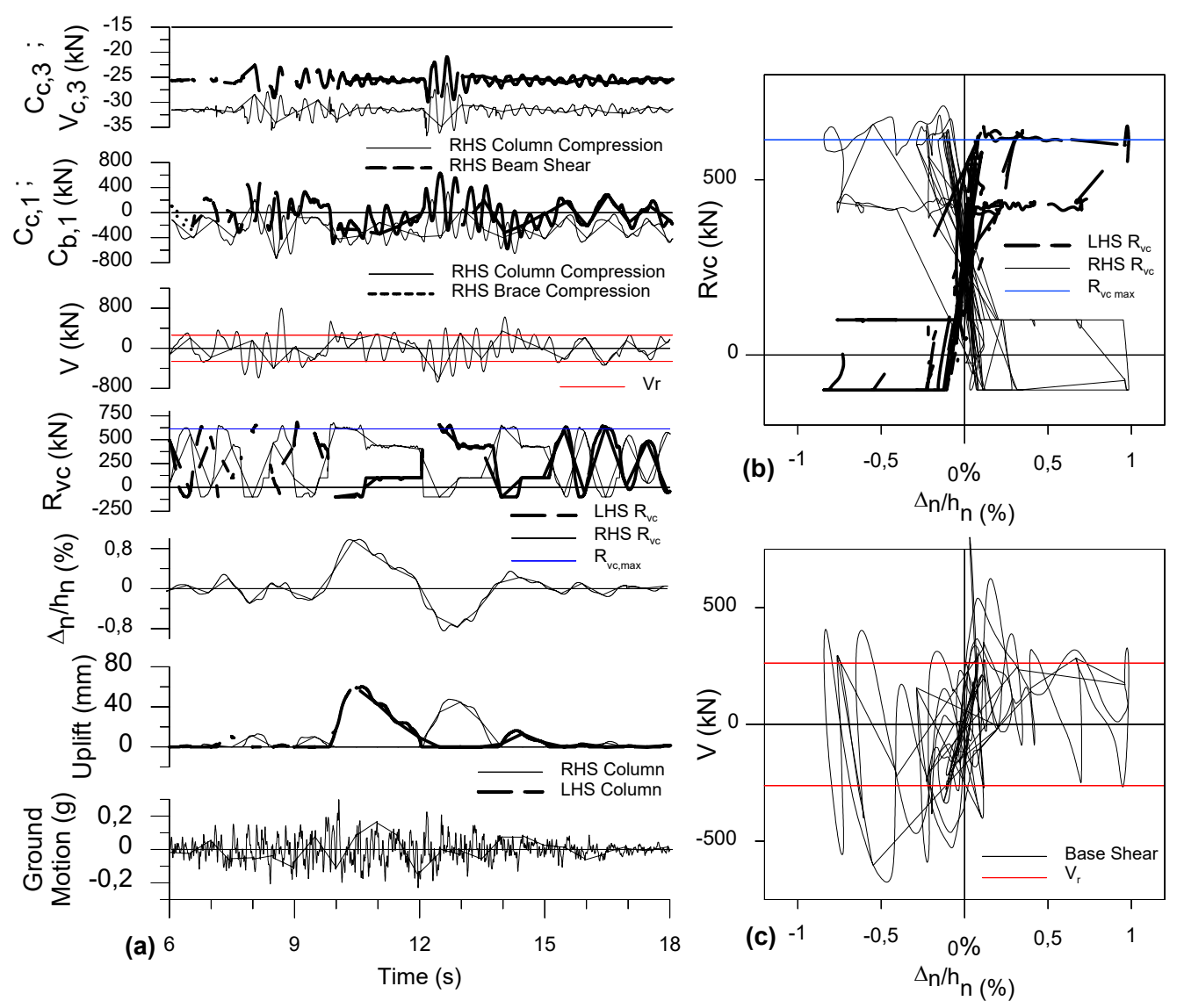

Figure 5 Response of the M3C RBF to an M7.0 event: a) Time histories of ground motion and key response parameters; b) Hysteretic response of vertical reactions column bases; and c) Base shear hysteretic response.

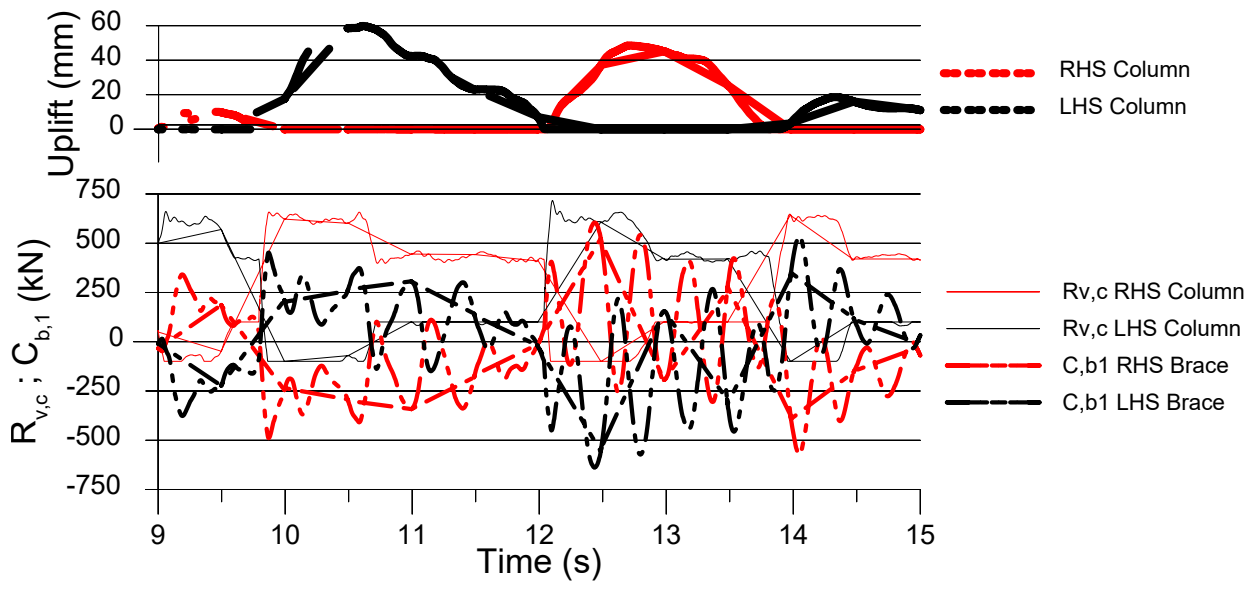

Figure 6 Close-up of the column and brace force responses at the first-storey of the M3C RBF subjected to an M7.0 event.

In the bottom graph of Figure 6, response histories of the axial loads $C_{\mathrm{b}, 1}$ in the two braces at the first level are also plotted. As shown, these brace force responses are characterized by significant oscillations at a frequency of approximately $3 \mathrm{~Hz}$, which corresponds to the second lateral vibration mode of the fixed based frame $\left(T_{2}=0.36 \mathrm{~s}\right.$ in 
Table 1). Higher mode properties of frames which rock at their bases remain nearly unchanged upon rocking [37] and the figure shows that the frame's second mode can be markedly excited during rocking, which induces high brace forces and, thereby, storey shears. For instance, at $t \approx 12.4 \mathrm{~s}$, brace forces reach approximately $600 \mathrm{kN}$ in tension and compression, which is $86 \%$ of the brace lower bound compressive strength. At the same time, the base shear reached approximately $700 \mathrm{kN}$, which corresponds to 2.7 times the value of $V_{\mathrm{r}}$ computed with Equation (9) for this structure. As shown, the amplitudes of the brace force oscillations seem to be correlated with the rocking response with larger amplitudes immediately after column impact followed by gradual reduction when columns are uplifting. Higher mode effects on storey shears can be readily seen on the base shear hysteretic response of Figure $5 \mathrm{c}$, which deviates significantly from the base shear response based on first mode rocking predicted in Figure $5 \mathrm{c}$. The highest base shears, well above $V_{\mathrm{r}}$, occur at small lateral displacements, thus following column impacts, as can be also observed in the base shear response history. When the rocking amplitude is large, the base shear matches more closely the $V_{\mathrm{r}}$ prediction.
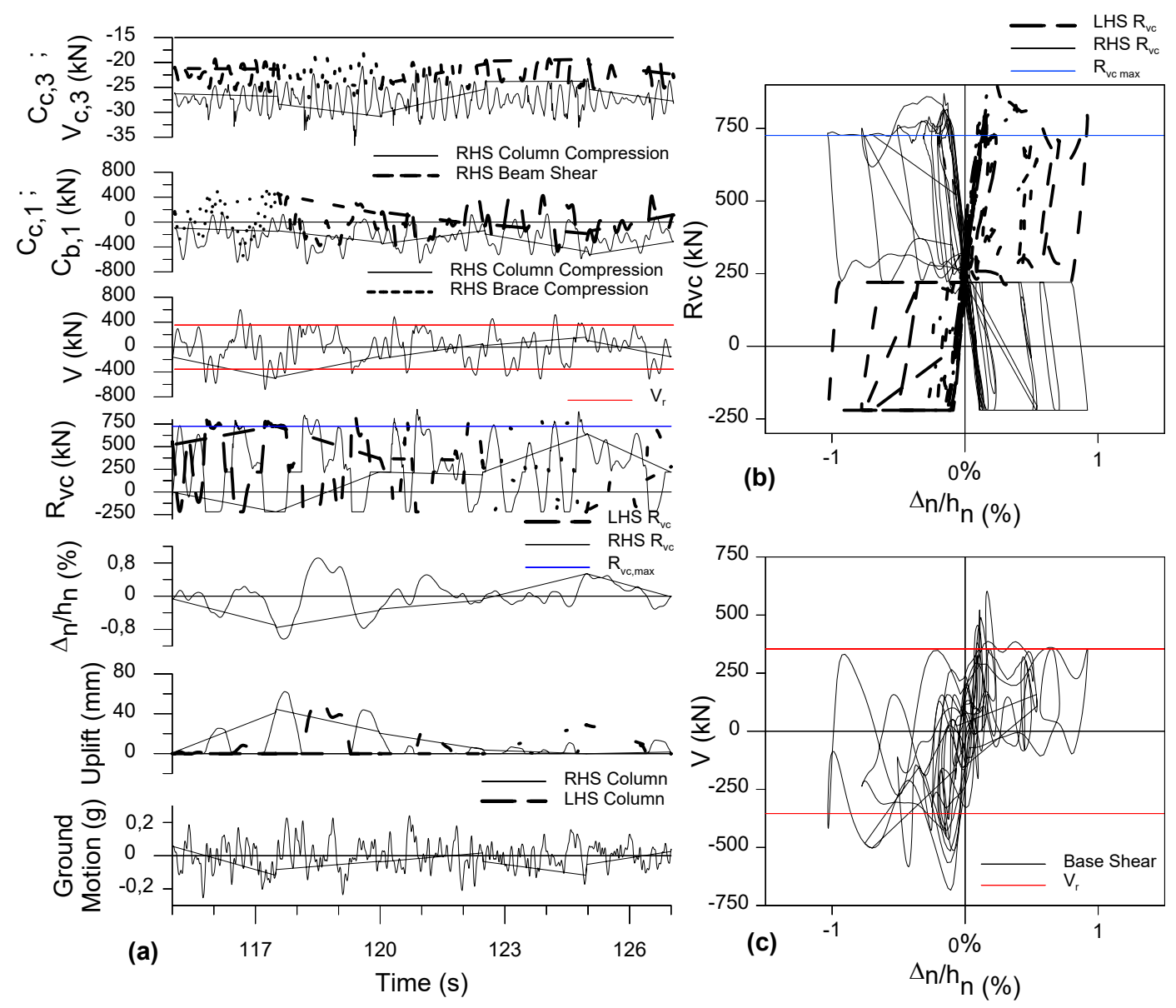

Figure 7 Response of the V3C RBF to an intraslab subduction event: a) Time histories of ground motion and key response parameters; b) Hysteretic response of vertical reactions column bases; and c) Base shear hysteretic response.

In Figure 5a, higher mode effects on brace forces also influence the column axial loads as illustrated by the correlation between the RHS column force $C_{\mathrm{c}, 1}$ and RHS brace force $C_{\mathrm{b}, 1}$ response histories in the first storey. A closer correlation exists when the column is in the air and the vertical component of the brace force must be resisted by the column. The top most response history graph in the figure shows the correlation between the axial load in the third storey segment of the RHS column $\left(C_{c, 3}\right)$ and the shear in the roof beam framing into that column $\left(V_{b, 3}\right)$. The axial load in this column segment is only due to the roof beam shears (no braces connected to the column top); the 
match between the two force signals indicates that the oscillations in column axial loads are due to vertical vibration of the roof beams that are induced by column impact.

Similar information to that shown in Figure 5 is provided in Figure 7 for the 3-storey frame V3C under an intraslab subduction ground motion event. No major differences can be observed between the M $3 \mathrm{C}$ and $\mathrm{V} 3 \mathrm{C}$ building responses, except that higher mode effects on storey and base shears are less pronounced for the latter, the base shear hysteresis being closer to that obtained from first mode rocking response in Figure $3 c$. This can be explained by the shorter dominant period of the ground motions in eastern Canada compared to western Canada. The effects of column impact on base shear, $R_{\mathrm{vc}}$, and roof beam vibrations ( $V_{\mathrm{b}, 3}$ versus $\left.C_{\mathrm{c}, 3}\right)$ are still clearly visible, however. Table 7 presents the main response parameters for all buildings. For each response parameter, the largest mean value of the different earthquake suites is presented.

Table 7 Mean value of response parameters.

\begin{tabular}{ccccccccc}
\hline Case & M2C & M3C & M2E & M3E & V2C & V3C & V2E & V3E \\
\hline Uplift $(\mathrm{mm})$ & 78.2 & 55.1 & 83.9 & 90.2 & 115.7 & 88.7 & 125.8 & 130.7 \\
\hline$\Delta_{\mathrm{n}} / h_{\mathrm{n}}(\%)$ & 1.27 & 0.94 & 1.37 & 1.49 & 1.85 & 1.44 & 2.02 & 2.12 \\
\hline$\Delta / h_{\mathrm{s}}(\%)$ & 1.19 & 0.91 & 1.23 & 1.51 & 1.83 & 1.56 & 2.12 & 2.18 \\
\hline$R_{\mathrm{vc}} / R_{\mathrm{vc} . \max }$ & 1.26 & 1.14 & 1.13 & 1.22 & 1.55 & 1.28 & 1.74 & 1.43 \\
\hline$V / V_{\mathrm{r}}$ & 2.22 & 2.77 & 1.92 & 2.18 & 1.77 & 1.99 & 1.46 & 2.00 \\
\hline$A_{\mathrm{h} .1}(\mathrm{~g})$ & 0.38 & 0.55 & 0.54 & 0.70 & 0.43 & 0.95 & 0.60 & 1.25 \\
\hline$A_{\mathrm{h} .2}(\mathrm{~g})$ & - & 0.28 & - & 0.31 & - & 0.30 & - & 0.44 \\
\hline$A_{\mathrm{h} . \mathrm{n}}(\mathrm{g})$ & 0.30 & 0.41 & 0.45 & 0.50 & 0.40 & 0.38 & 0.55 & 0.49 \\
\hline$A_{\mathrm{v} .1}(\mathrm{~g})$ & 0.54 & 0.35 & 0.76 & 0.55 & 1.22 & 0.78 & 1.75 & 1.19 \\
\hline$A_{\mathrm{v} .2}(\mathrm{~g})$ & - & 0.35 & - & 0.54 & - & 0.81 & - & 1.13 \\
\hline$A_{\mathrm{v} . \mathrm{n}}(\mathrm{g})$ & 1.01 & 0.26 & 1.35 & 0.45 & 2.30 & 0.75 & 2.72 & 1.17 \\
\hline$C_{\mathrm{b} .1} / Q_{\mathrm{CL}}$ & 0.75 & 0.98 & 0.80 & 0.88 & 0.73 & 0.93 & 0.93 & 1.08 \\
\hline$C_{\mathrm{b} .2} / Q_{\mathrm{CE}}$ & - & 0.59 & - & 0.62 & - & 0.62 & - & 0.70 \\
\hline $\mathrm{C}_{\mathrm{b} . \mathrm{n}} / \mathrm{Q}_{\mathrm{CE}}$ & 1.43 & 1.95 & 1.46 & 1.66 & 1.16 & 1.60 & 1.27 & 1.69 \\
\hline $\mathrm{C}_{\mathrm{c} .1} / \mathrm{Q}_{\mathrm{CL}}$ & 1.05 & 0.80 & 0.93 & 0.79 & 0.89 & 0.80 & 1.18 & 0.87 \\
\hline & & & & & & & & \\
\hline
\end{tabular}

\subsection{Roof drifts, brace forces and column forces}

Drifts and member forces are critical response parameters for this retrofit option; as such, these parameters are examined first in this section. Mean values and mean plus or minus one standard deviation $(\mu \pm \sigma)$ values of the roof drifts and axial compression loads in the braces and columns are given in Figure 8. As shown in Table 7, good correlation exists between the largest storey drift $\left(\Delta / h_{\mathrm{s}}\right)$ and the roof drift; only the latter is presented in the figure. Brace loads are given at every level, whereas column loads are given only at the first level.

The results show that drifts are generally higher for structures located on soft (class E) soils and structures in western Canada. This trend can be attributed to the relatively longer dominant periods exhibited by the ground motions for these conditions. It is also observed that higher drifts were obtained for the 2-storey frames compared to those for the 3 -storey buildings. It must be noted that drifts depend on the $F_{\mathrm{s}}$ value assigned to the ED devices; different results would have been obtained with different ED activation loads. Except for buildings located on soft soils, Vancouver, peak drift ratios in all buildings are below 1.5\%, which is below the $2 \%$ limit specified in ASCE 41 for the Position Retention (N-B) performance level for most non-structural components. Drifts for those buildings slightly exceed the $2 \%$ limit, which could be corrected at the final design stage by specifying higher capacity ED devices. ASCE 41 also 
prescribes a more severe $1 \%$ drift acceptance criterion for door systems and heavy partitions, both for Position Retention and Life-Safety performance levels. This criterion would be met for the 3-storey structures in Montreal. For the other cases, increasing the energy dissipation capacity could be examined as a solution to satisfy this requirement. However, increasing $F_{\mathrm{s}}$ may lead to higher force demands on members and/or negatively affect the re-centring capacity of the frames. For the latter, alternative ED systems that improve re-centring could be used, as discussed in Section 5.
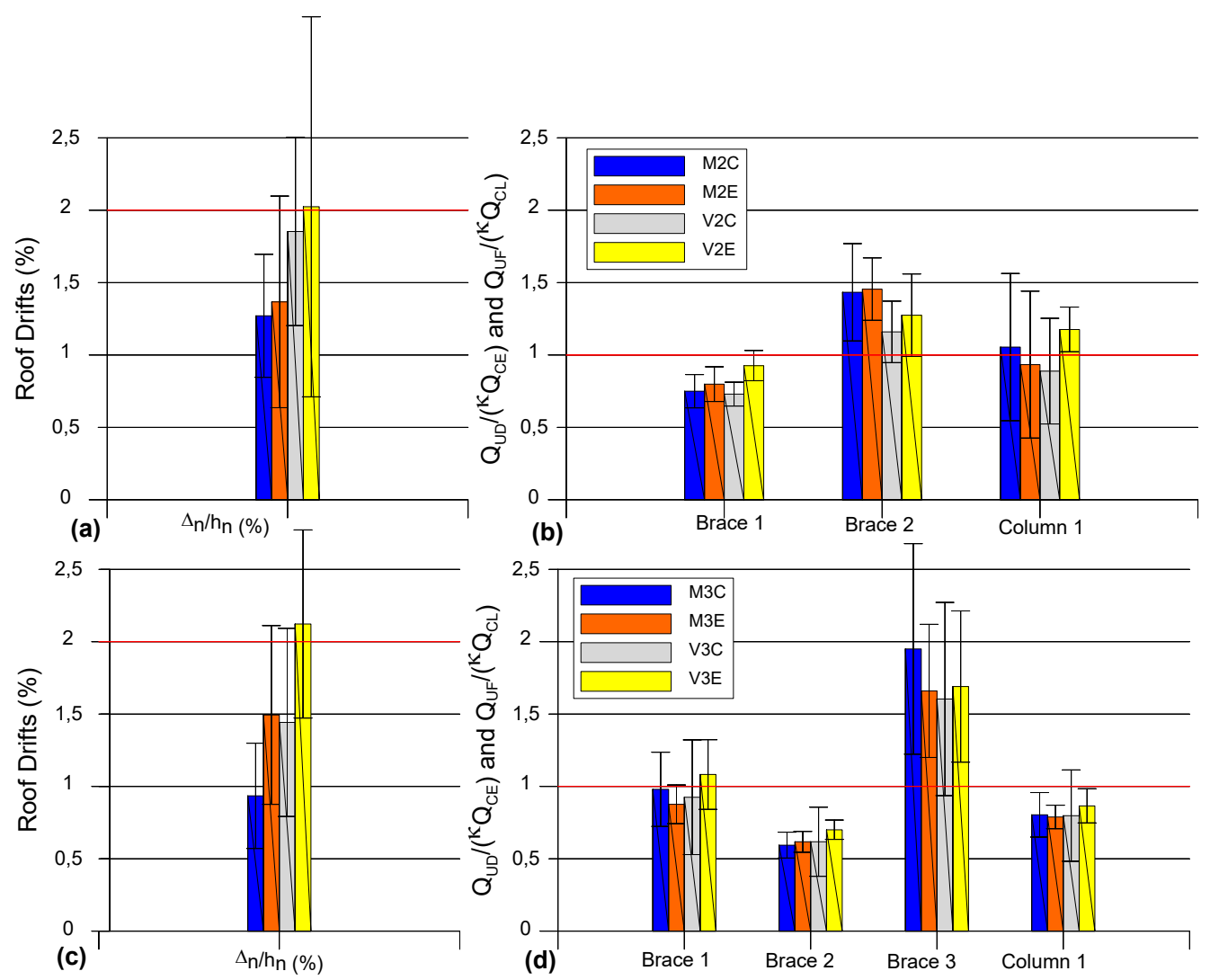

Figure 8 Peak roof drifts in the 2-storey (a) and 3-storey (c) buildings; peak brace and column axial compression loads in the 2-storey (b) and 3-storey (d) buildings.

Column uplift is closely related to roof displacement, which can be verified by comparing the results for both parameters in Table 7. Except for building V2E, uplift values vary between 55 and $115 \mathrm{~mm}$, which would induce rotations ranging between 0.85 to 1.77 radians to the beam-to-column connections of the adjacent beams framing into the rocking columns. Past tests have shown that typical shear connections with shear tabs or web angles can accommodate this demand without losing their gravity load capacity [38].

In Figure 8 (b) and (d), brace forces $Q_{\mathrm{UD}}$ are normalized with respect to their expected strengths $Q_{\mathrm{CE}}$, whereas column forces $Q_{\mathrm{UF}}$ are presented with respect to their lower-bound strengths $Q_{\mathrm{CL}}$. For the bracing members, a ratio of 1.0 is required to achieve ASCE 41 Immediate Occupancy structural performance $(m$ factor $=1.0)$ and avoid the severe unbalanced brace loading condition for the beams. The results show that the RBF system can limit brace forces below $Q_{\text {CE }}$ in the first level of all buildings and the second level of all 3-storey buildings. However, the margin between brace capacities and brace forces from first mode rocking response in Section 4.1 was not sufficient to accommodate the additional brace force demand imposed by higher mode response in the topmost storey of the 2-and 3-storey buildings at all sites. As shown, braces (and their connections) at these levels will need to be strengthened by factors of 1.2-1.4 for the 2-storey frames and 1.4-2.0 for the 3-storey frames, respectively, depending on the location and site class. Stronger reinforcement would be needed in eastern Canada, likely because of the greater higher mode response expected under the ground motions in that part of the country. For the columns, ratios $Q_{U F} / Q_{C L}$ are close to or less than 1.0 in all cases, despite the observed additional demand from column impact, meaning that the existing columns could be kept unchanged. 
This first series of results indicate that the proposed RBF retrofit scheme would only require reinforcement of the braces at the top storey to achieve IO structural performance under $2 \%$ in 50 years hazard, which could represent an attractive alternative to the traditional retrofit method aimed at satisfying current code strength (and ductility) requirements. For the 3-storey buildings in Montreal, full compliance to performance objective 1-B can be obtained including Position Retention performance for all non-structural components. For the other cases studied, additional modifications to the proposed RBF system will be needed to reduce peak drift response to satisfy the acceptance criteria for door systems and heavy partitions.

\subsection{Base shear and vertical base reactions}

Reliable assessment of the base reactions is necessary to design the anchor blocks and to verify the capacity of the existing foundations. As described, base shear amplification compared to static predictions due to higher mode response is expected and must be considered in design. Ratios $V / V_{\mathrm{r}}$ are given in Figure 9 for all frame configurations. For the 2-storey buildings studied herein, the results indicate that a factor of 2.0 must be considered in the calculations. For the 3-storey frames, a factor of 2.0 is still suitable for western Canada, but a higher value (up to 2.7) would be necessary for eastern Canada. These values compare well with values predicted by Steele and Wiebe [39] for low-rise rocking braced frames.
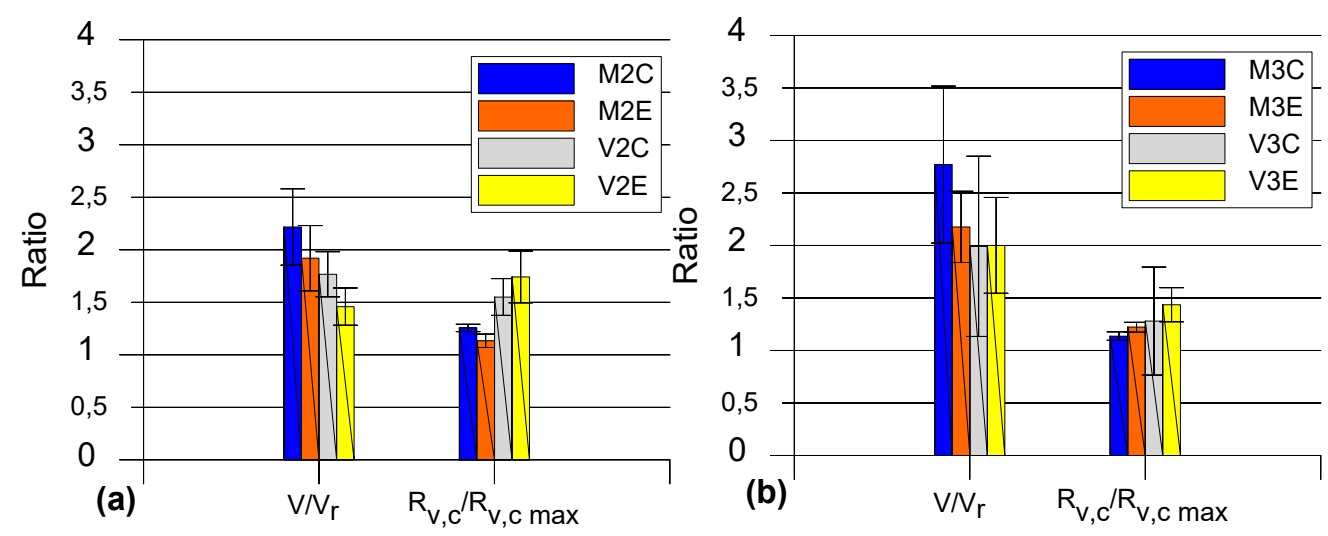

Figure 9 Base shear and vertical base reaction demands for: a) 2-storey; b) 3-storey buildings.

Ratios between the $R_{\mathrm{vc}}$ values from the response history analysis and the $R_{\mathrm{vc}, \max }$ values predicted by Equation 6 are also presented in Figure 9. For eastern Canada, an amplification factor of 1.2 would seem appropriate to accommodate the additional demand from higher mode response and column impact. For Vancouver, the amplification is higher, varying between 1.3 and 1.7 .

\subsection{Accelerations}

Floor and roof accelerations are also important response parameters that must be considered in the context of seismic retrofit for enhanced seismic performance. Vertical accelerations are induced in the gravity system connected to the rocking frames, in addition to the horizontal accelerations resulting from lateral response. Both parameters are discussed herein for the frames subjected to horizontal ground motions alone. Possible additional effects of vertical ground motions are discussed in Section 5.

ASCE 41 does not specify acceptance criteria for horizontal and vertical accelerations that can be sustained by nonstructural components. Rather, equations are given in ASCE 41 to determine forces that are induced by horizontal and vertical accelerations, and the accelerations used in these equations are determined either from structural analysis or from simple equations. In this section, accelerations obtained from response history analyses of the RBFs are compared to those predicted by the ASCE 41 equations to determine if these equations can be used for rocking braced 
frames. For the horizontal forces, ASCE 41 employs Equation (10) to predict the maximum anticipated horizontal acceleration $A_{\mathrm{h}, \mathrm{x}}$ at level $\mathrm{x}$ of a building:

$$
A_{h, x}=0.4 S_{s}\left(1+\frac{2 x}{h_{n}}\right)
$$

where $S_{\mathrm{s}}$ is the spectrum value for short periods, i.e. $S_{\mathrm{a}}(0.2 \mathrm{~s})$ in the $2015 \mathrm{NBCC}$, and $x$ is the height of the storey under consideration. The values of $A_{\mathrm{h}, \mathrm{x}}$ for the two locations and the two building heights are given in Table 8; ratios between the peak horizontal accelerations from the response history analyses and $A_{\mathrm{h}, \mathrm{x}}$ are given in Figure 10a and $\mathrm{c}$. As shown, peak horizontal accelerations in the RBFs are generally lower than those predicted by ASCE 41, except at the first storey of the 3-storey frame V3E. For this structure, it is expected that the relatively higher value of $F_{\mathrm{s}}$ contributed to this response, suggesting that proper consideration should be given to peak floor accelerations when selecting $F_{\mathrm{s}}$. The results also show that accelerations do not increase linearly with the height, as implied by Equation (10). Except for the V3E case, the results indicate that an RBF retrofit solution does not lead to excessive horizontal accelerations compared to code predictions. In fact, for many of the cases studied, peak floor accelerations are significantly lower than assumed in ASCE 41, which can be seen as a positive outcome for the retrofit of existing non-structural components that have not been designed for seismic demand.

Table 8 Predicted horizontal accelerations (g) - ASCE 41

\begin{tabular}{ccccccccc}
\hline Case & M2C & M3C & M2E & M3E & V2C & V3C & V2E & V3E \\
\hline Storey 1 & 0.490 & 0.409 & 0.514 & 0.429 & 0.696 & 0.581 & 0.842 & 0.703 \\
\hline Storey 2 & - & 0.562 & - & 0.589 & - & 0.798 & - & 0.965 \\
\hline Roof & 0.714 & 0.714 & 0.748 & 0.748 & 1.014 & 1.014 & 1.227 & 1.227 \\
\hline
\end{tabular}
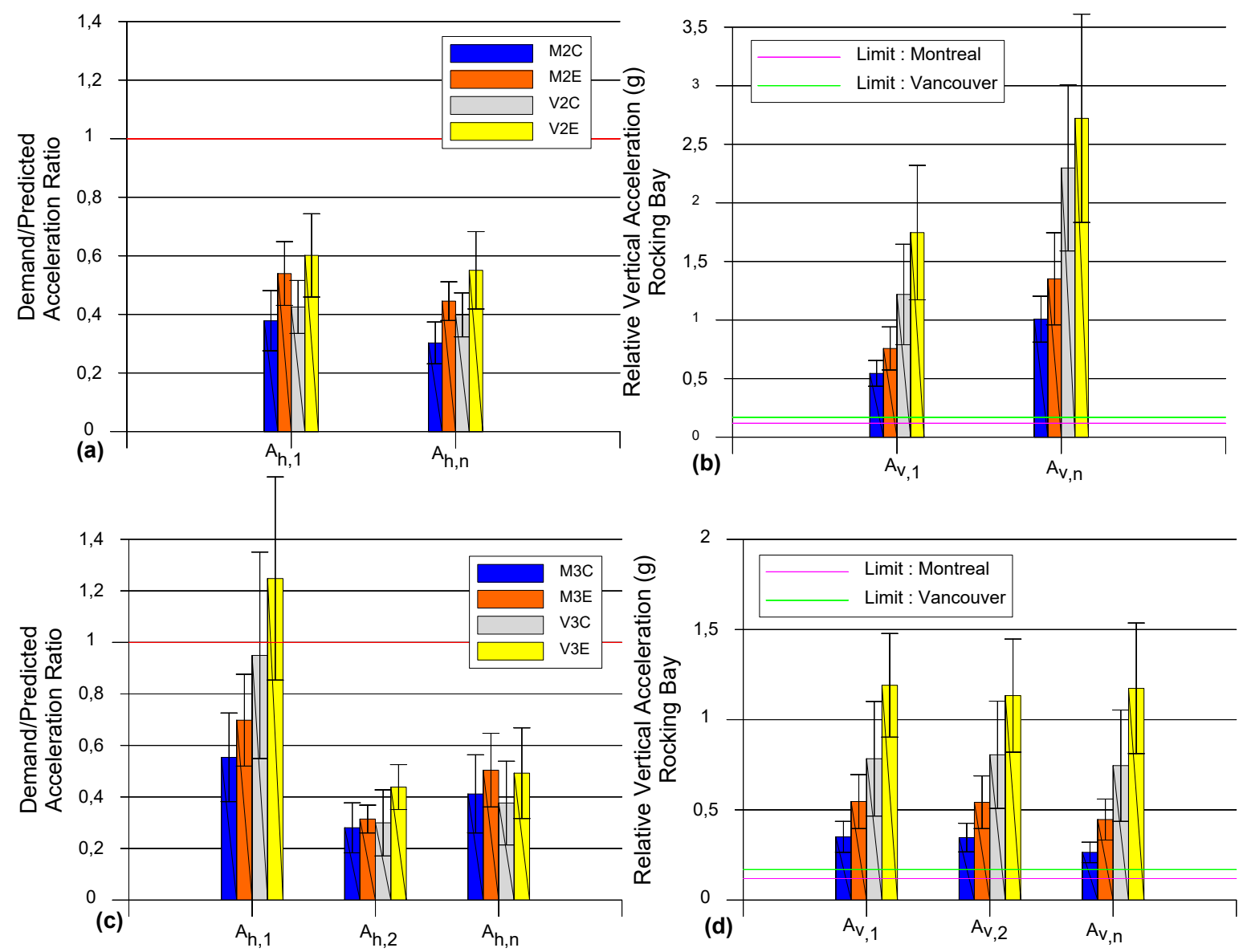

Figure 10 Floor and roof acceleration demands: Horizontal accelerations in the 2-storey (a) and 3-storey (c) buildings; Vertical accelerations in the 2-storey (b) and 3-storey (d) buildings. 
ASCE 41 recommends the following expression for vertical accelerations $A_{\mathrm{v}, \mathrm{x}}$ that are used to calculate vertical forces:

$$
A_{v, x}=0.2 S_{s}
$$

This equation gives values of $0.12 \mathrm{~g}$ in Montreal and $0.17 \mathrm{~g}$ in Vancouver. These values are constant over the frame height. Relative vertical accelerations from analysis (gravity is not included) are presented in Figure 10b and d. The accelerations are those recorded at the joist to beam connection points along the beams framing into the rocking columns. Two main trends can be observed. Firstly, in all cases, higher vertical accelerations are observed for the E sites (compared to $\mathrm{C}$ sites) and in western Canada (compared to eastern Canada). This trend is consistent with that observed for the roof lateral displacements and, thereby, column uplifts. Secondly, vertical accelerations at the roof level of all 2-storey frames are significantly higher than those at the first level of these structures and those obtained at the roof level of the 3-storey frames. This relatively higher acceleration demand at the top of the 2-storey RBFs can be attributed to the fact that energy resulting from column impact can be transmitted more directly to the roof in that structure. For the 3-storey frames, vertical accelerations increase only moderately with floor elevation.

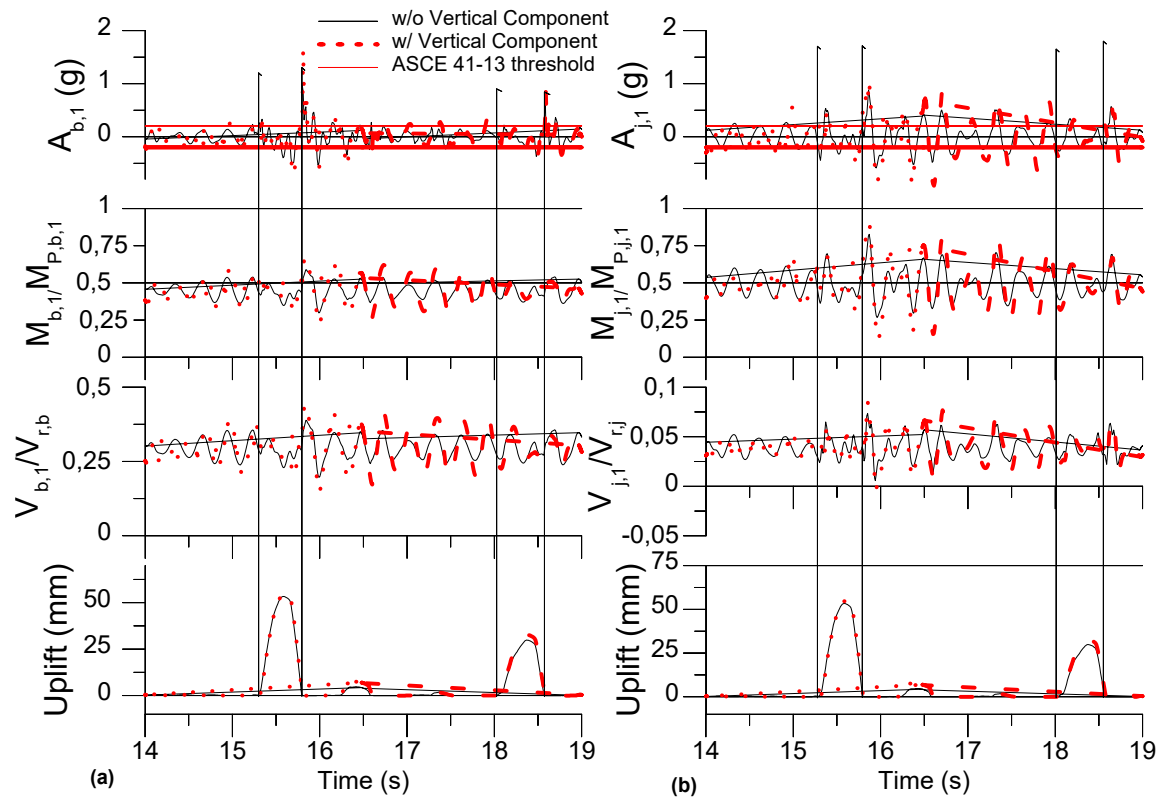

Figure 11 Vertical acceleration, moment and shear demands on the first-storey beam (a) and joists (b) of the V3E building subjected to horizontal and horizontal plus vertical ground motion components from a crustal event.

At both locations, the vertical accelerations in Figure 10 exceed by a large margin the acceleration values predicted by Equation (11), with values reaching up to $3 \mathrm{~g}$ and $1 \mathrm{~g}$ at the roof of buildings V2E and V3E, respectively. This can be compared to the ASCE 41 prediction of $0.17 \mathrm{~g}$. Examination of the acceleration response history of the beams and joists shows that maximum values occur after column impact upon rocking. This is illustrated in Figure 11 for the beam $(\mathrm{b}, 1)$ and the joists $(\mathrm{j}, 1)$ at the first level of building V3E under a crustal event. Shear $(\mathrm{V})$ and moment $(\mathrm{M})$ are respectively compared to the shear resistance $\left(V_{r}\right)$ and the plastic moment $\left(\mathrm{M}_{\mathrm{p}}\right)$ of the considered members. The results are given for the horizontal ground motion component with and without the vertical ground motion component. The former case is discussed in Section 5. Between two consecutive impacts, beams and joists vibrate at their natural period with a gradual reduction in amplitude due to damping. Member responses are only slightly affected by column uplifting; however, the impact of the column base with the foundations clearly triggers higher beam and joist vibrations. As expected, impact effects are more pronounced for the beam than the joists, as the former is connected to the columns. Vertical accelerations must therefore be determined from nonlinear dynamic analysis explicitly considering rocking response. Figure 11 also shows the variation of the bending moments at the members' mid-spans as well as end shears. Both parameters essentially vary in phase with the members' vertical accelerations. However, for this structure, the ratio between the factored gravity loads used to design the floor beams and joists are 1.7 times higher than the gravity loads considered in the seismic response analysis, which provided sufficient margin to safely resist the additional demand from vertical accelerations. It must also be realized that these accelerations only occur in 
the members directly connected to the rocking frame. The rest of the building structure is expected to experience vertical accelerations as predicted by Equation (11).

\section{Complementary analyses}

Complementary response analyses were performed to study the influence of the force versus deformation hysteretic behaviour of the ED devices and the influence of the vertical components of the ground motions.

\subsection{Influence of the ED devices}

Two additional ED devices were examined: Ringfeder $\odot$ springs (RFS) and slender steel bars yielding in tension (YB). Their force versus deformation hysteretic responses are compared to friction in Figure 12. Ringfeder (C) springs exhibit a self-centring hysteresis in tension combined with limited energy resulting from internal friction. The system can then enhance the re-centring capability of the RBF. This ED element has been used in RBF applications in New Zealand. Slender bars yielding in tension buckle in compression and therefore accumulate permanent plastic elongation at each yielding excursion and exhibit a pinched hysteresis in tension. However, these bars offer little resistance to the downward movement of the column, which eases RBF re-centring.

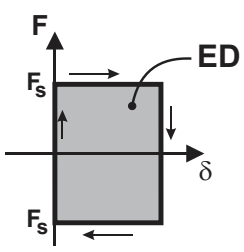

Friction

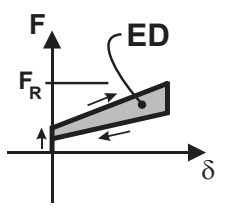

Ringfeder Springs

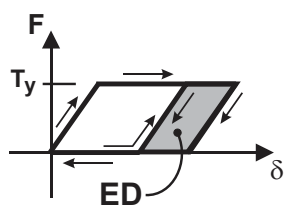

Tension Bar

Figure 12 Force versus deformation hysteretic response of the ED systems studied.

Both ED systems could be modelled in the numerical SAP model to compare the frame rocking response for the case $T_{\mathrm{y}}=F_{\mathrm{s}}$. For the RFS, the spring properties were determined in accordance with the supplier's guidelines such that $F_{\mathrm{R}}$ be the same as $F_{s}$ at peak displacements obtained with the friction system. Column uplift response histories obtained with the three ED systems are presented in Figure 13a for the M3C structure. For this case, similar maximum uplift responses were obtained using the friction and YB dissipators. The RFS shows higher maximum uplift values in the cycle after $12 \mathrm{~s}$. The three ED systems however resulted in similar $R_{\mathrm{vc}}$ forces in Figure $13 \mathrm{~b}$ at the base of the LHS column. The RFS element induced higher $R_{\mathrm{vc}}$ at large positive drifts. This is due to the RFS element in the RHS column reaching its deformation capacity during uplifting, which resulted in a sudden increase in tension resistance in that column and a higher compression in the LHS column. The main difference between the three devices is the amount of energy they can dissipate, as defined by the area enclosed by the force versus drift ratio hysteretic curves in the third quadrant of the graph of Figure $13 \mathrm{~b}$. 

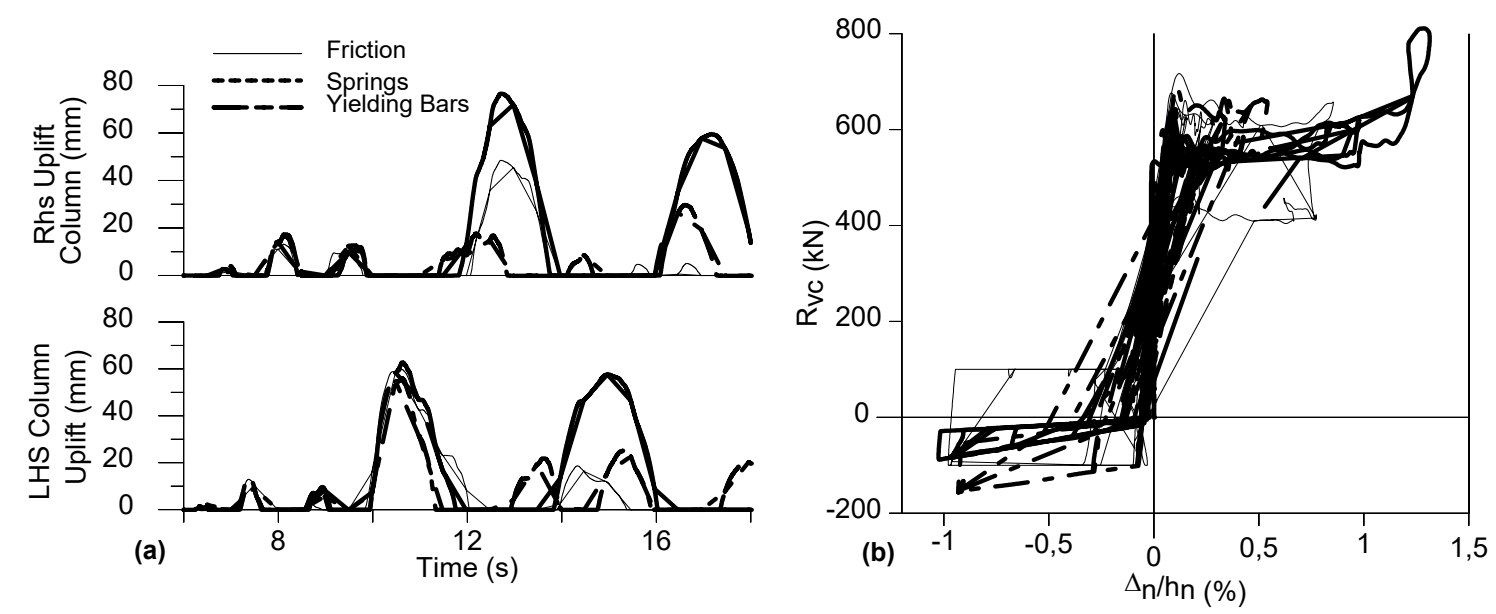

Figure 13 Comparison of the column and brace responses obtained with three ED devices for the $\mathrm{M} 3 \mathrm{C}$ building under a M7.0 event a) Column uplift and brace axial load response histories; b) Force versus drift ratio hysteretic response of the vertical reaction at the column base

In Figure 14, mean values of the response parameters obtained with the RFS and YB ED systems are divided by the values obtained with the friction ED for the M3C building. As shown in Figure 14a, the ED system has virtually no effect on the brace and column force demands. In Figure 14b, using and RFS or YB system produces higher drifts compared to friction, respectively $30 \%$ and $32 \%$, which is attributed to their lower energy dissipation capacity. Vertical accelerations in the lower two storeys of the structure are also significantly increased with the RFS and YB devices. This was expected; both devices tend to facilitate column repositioning and frame re-centring, which can result in higher impact loads. This comparative study shows that the friction ED can better control column uplift and drifts without inducing higher forces and accelerations, in contrast to the other two systems.
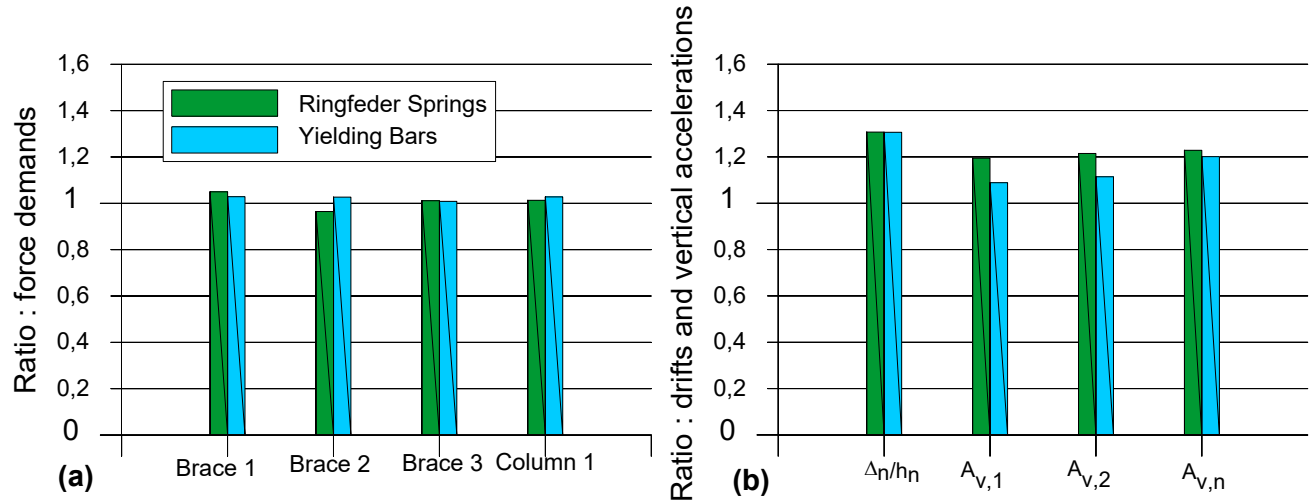

Figure 14 Influence of the ED devices on the response of the M3C building under an M7.0 event: a) Brace and column axial loads; b) Drifts and vertical accelerations (values are given with respect to Friction ED)

\subsection{Effects of the vertical ground motion component}

The influence of the vertical ground motion component is studied for the V3E structure under crustal events. In Figure 11 , floor accelerations and member forces are increased when vertical ground motions are included. As also shown in this figure, column impacts still control peak values and subsequent oscillation response. The effects of vertical ground motion therefore vary depending on phase differences between ground motion and frame response signals. Figure 15a shows the statistics of the effects of vertical ground motions on the peak vertical accelerations of the beams. Overall, the effect is limited. Figure $15 \mathrm{~b}$ shows that vertical ground motion effects are also limited on column forces and even smaller on brace axial forces. As shown in Figure 16, the limited influence of vertical ground motions for this structure can be attributed to the difference in the frequency content between the vertical components of the studied ground 
motions in comparison with the natural period of vibration of the floors and roof. Nevertheless, these effects should be considered when assessing the gravity framing members.

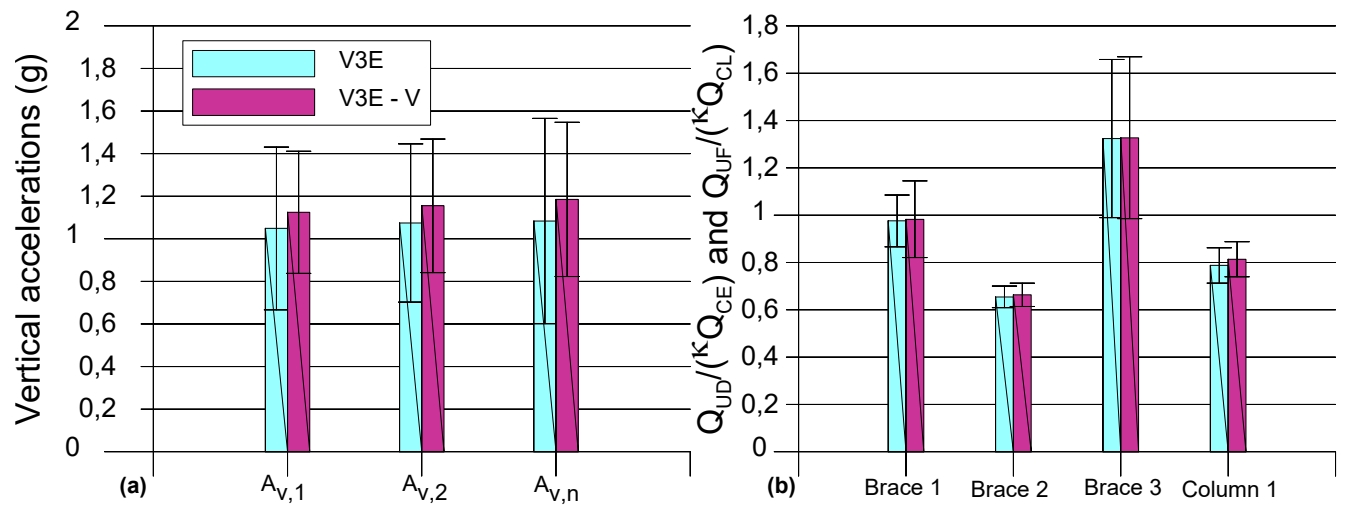

Figure 15 Influence of the vertical acceleration component of the crustal ground motions for buildings V3E on: a) vertical accelerations of beams, and b) Braced frame member forces.

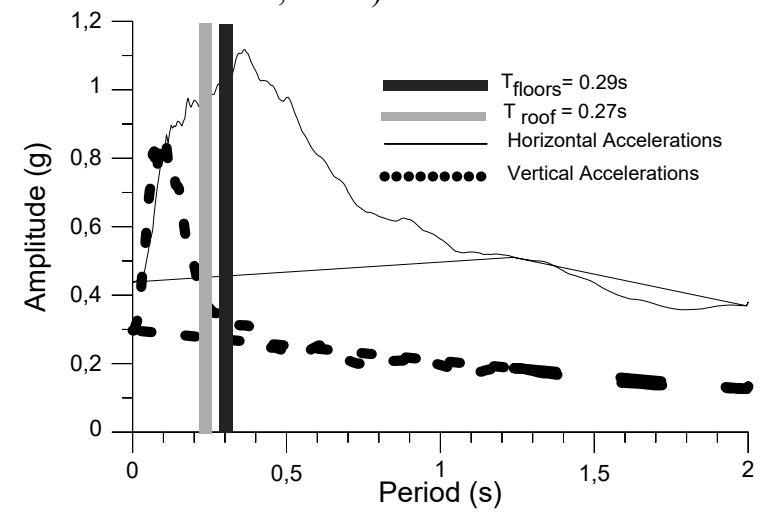

Figure 16 Average response spectra of the horizontal and vertical ground motion components for site class E in

Vancouver.

\section{Conclusions}

The applicability of rocking braced frames (RBFs) relying on gravity loads rather than post-tensioning elements for re-centring was examined for the seismic retrofit of low-rise steel buildings designed prior to the implementation of the seismic design and detailing requirements for steel structures in Canadian codes. The RBFs also included friction energy dissipative (ED) devices to restrain column uplift and control drifts. The buildings, 2 and 3 storeys in height, were assumed to be located on firm ground and soft soil sites in eastern and western Canada. Seismic assessment using the provisions of the 2015 NBCC revealed that the structures in their existing conditions did not possess sufficient lateral resistance to achieve life safety performance under a seismic hazard corresponding to a probability of exceedance of $2 \%$ in 50 years. Seismic evaluation using the ASCE 41-13 Standard showed that although the bracing members could meet the acceptance criteria for life safety, beams and columns would need to be substantially reinforced to achieve these objectives.

The potential for the RBF retrofit scheme was initially verified by studying the static equilibrium of the frames upon rocking. This also provided criteria for determining the activation loads of the ED devices. Final ED capacities were set to allow for full re-centring response, while limiting drifts to $2 \%$ of height. The retrofit approach was deemed appropriate to achieve ASCE 41 1-B performance level under $2 \%$ in 50 years hazard, i.e. Immediate Occupancy structural performance and Position Retention performance for non-structural components. Response history analyses under site representative ground motion ensembles were performed to investigate the behaviour and performance of the proposed RBF seismic retrofit strategy.

The following conclusions can be drawn on the behaviour of the proposed RBF system: 
- The system exhibited a self-centring response with no residual lateral deformations. Deformations imposed by rocking to adjacent structural members are not expected to cause structural damage.

- Column impact upon rocking induced higher compression loads in the columns and vertical dynamic response of the floor and roof structural members connected to the gravity system. The maximum vertical column reactions can be taken as 1.5 times the value predicted from static equilibrium. Because of reduced gravity loads considered in the load combination with earthquakes, floor and roof framing members could resist the additional demand from dynamic vertical response.

- Seismic induced axial loads in braces and columns were significantly reduced due to frame rocking, but these forces were also highly amplified by higher lateral mode response. Dynamic amplification was most severe for the braces at the building top level. Amplification was also more pronounced for the taller (3-storey) frames and in structures located in eastern Canada due to shorter ground motion dominant periods in that region. The dynamic base shears reached between 2.0 to 2.5 times the rocking base shear $V_{\mathrm{r}}$ predicted from static equilibrium.

The conclusions on the ASCE 41 performance levels that could be reached with the proposed RBF system are as follows:

- Immediate Occupancy structural performance can be achieved under $2 \%$ in 50 years seismic hazard for all structures provided that the braces and their connections are reinforced at the top storeys of the buildings. Strengthening levels of 1.5 and 2.0 are required for the 2- and 3-storey buildings, respectively.

- Peak storey drifts remained equal to or below $2.0 \%$ of height in all structures, which indicates that Position Retention performance can be achieved for most non-structural components. A stricter limit of $1 \%$ drift ratio is imposed for components such as door systems and heavy partitions. This criterion could be satisfied only for the 3-storey structures in eastern Canada. For the other structures, higher ED capacity would be needed to further control lateral displacements; however, caution must be exercised when applying this modification as it may lead to higher member force demands and affect self-centring capabilities.

- Peak horizontal accelerations from analyses remained below the values predicted by ASCE 41 for the calculation of the horizontal forces acting on non-structural components.

- Peak vertical accelerations in the gravity system directly connected to the rocking frames exceeded by a large margin the values predicted by ASCE 41 for the calculation of the vertical forces acting on non-structural components. These vertical accelerations are induced by column impact upon rocking and can only be predicted using nonlinear dynamic analysis. Vertical accelerations in the rest of the building are expected to be same as in any other regular buildings.

The complementary analyses showed that:

- For the M3C structures, friction ED devices can control drifts better than ED systems with Ringfeder springs or bars yielding in tension having similar force capacities. The choice of the ED devices used in the system has a limited influence on the maximum forces that are induced in the structure.

- For the V3E structure subjected to crustal ground motions, consideration of the vertical components of the ground motions has a negligible influence on the structure's rocking response and vertical accelerations in the gravity system, mainly because their dominant period was shorter than the structure vertical vibration periods and vertical accelerations were governed by column impact response.

This study was limited to numerical simulations; the results and findings must be validated through physical testing. Dynamic (shake table) testing is needed to capture column impact response and amplification due to higher mode response. Physical testing is also needed to verify the capacity of existing structures to accommodate the deformations to be induced by rocking. Further research should also aim at developing simple design guidelines and methods to achieve effective rocking braced frame designs in day-to-day practice.

\section{Acknowledgements}

Funding for this research was provided by the Fonds de Recherche du Québec - Nature et technologies (FRQNT) of the Government of Quebec, Canada. 


\section{References}

1. Mitchell, D., Paultre, P., Tinawi, R., Saatcioglu, M., Tremblay, R. Elwood, K., Adams, J., and DeVall, R. Evolution of Seismic Design Codes in Canada. Canadian Journal of Civil Engineering 2010; 37 (9): $1157-1170$.

2. Tremblay, R. Advances in seismic evaluation and retrofit of steel building structures under the Canadian Seismic Research Network. Proceedings $11^{\text {th }}$ Canadian Conference on Earthquake Engineering, Victoria, BC, 2015; Paper No. 99061.

3. Tremblay, R., Atkinson, G.-M., Bouaanani, N., Daneshvar, P., Léger, P., and Koboevic, S. Selection and scaling of ground motion time histories for seismic analysis using NBCC 2015. Proc. $11^{\text {th }}$ Canadian Conference on Earthquake Engineering, Victoria, BC, 2015; Paper No. 99060.

4. Jiang, Y., Balazadeh-Minouei, Y., Tremblay, R., Koboevic, S., and Tirca, L. Seismic assessment of existing steel braced frames designed in accordance with the 1980 Canadian code provisions. Proc. $7^{\text {th }}$ International Conference STESSA 2012, Santiago, Chile, 2012; 531-537.

5. Redwood, R. G., and Channagiri, V. S. Earthquake resistant design of concentrically braced steel frames. Canadian Journal of Civil Engineering 1991; 18(5), 839-850.

6. Tremblay, R. Evolution of the Canadian Seismic Design Provisions for Steel Structures since 1989. Proceedings CSCE 2011 General Conference \& Jagmohan Humar Symposium, Ottawa, ON, 2011.

7. Huckelbridge, A.A. Earthquake simulation tests of a nine story steel frame columns allowed to uplift. Report no. UCB/EERC-77/23. Earthquake Engineering Research Center, University of California, Berkeley, CA, USA. 1977.

8. Midorikawa, M., Azuhata, T., Ishihara, T., and Wada, A. Shaking table tests on seismic response of steel braced frames with column uplift. Earthquake Engineering and Structural Dynamics 2006; 35, 1767-1785.

9. Tremblay, R., Poirier, L.-P., Bouaanani, N., Leclerc, M., René, V., Fronteddu, L., and Rivest, S. Innovative viscously damped rocking braced steel frames. Proceedings $14^{\text {th }}$ World Conference on earthquake Engineering, Beijing, China, 2008, Paper No. 05-01-0527.

10. Pollino, M. and Bruneau, M. Seismic Testing of a Bridge Steel Truss Pier Designed for Controlled Rocking. Journal of Structural Engineering 2010; 136 (12), 1523-1532.

11. Sause, R., Ricles, J.M., Roke, D.A., Chancellor, N.B., and Gonner, N.P. Seismic performance of a self-centering rocking concentrically-braced frame, Proceedings $9^{\text {th }}$ US National and $10^{\text {th }}$ Canadian Conference on Earthquake Engineering, Toronto, Ontario, Canada 2010.

12. Wiebe, L., Christopoulos, C., Tremblay, R., and Leclerc, M. Mechanisms to limit higher mode effects in a controlled rocking steel frame. 1: Concept, modelling, and low-amplitude shake table testing, 2: Large-amplitude shake table testing. Earthquake Engineering and Structural Dynamics 2013; 42 (7), 1053-1086.

13. Eatherton, M.R., Ma, X., Krawinkler, H., Deierlein, G.G., and Hajjar, J.F. Quasi-Static Cyclic Behavior of Controlled Rocking Steel Frames. Journal of Structural Engineering, 2014; 140 (11), DOI: 10.1061/(ASCE)ST.1943-541X.0001005.

14. Eatherton, M.R., and Hajjar, J.F. Quasi Hybrid simulation testing of a self-centering rocking steel braced frame system. Earthquake Engineering and Structural Dynamics 2014; 43, 1725-1742. DOI: 10.1002/eqe.2419.

15. Ma X, Deierlein G, Eatherton M, Krawinkler H, Hajjar J, Takeuchi T, Kasai K, Midorikawa M, Hikino T. 2010. Large-scale shaking table test of steel braced frame with controlled rocking and energy dissipating fuses., Proceedings of the 9th US and 10th Canadian Conference on Earthquake Engineering, Toronto, Ontario, 2010

16. Wiebe, L., and Christopoulos, C. R $=100$ ? Toward codification of controlled rocking steel braced frames. Proceedings, $10^{\text {th }}$ US National Conference on Earthquake Engineering, Anchorage, Alaska, USA 2014.

17. Pollino, M. Seismic design for enhanced building performance using rocking steel braced frames. Engineering Structures 2015, 83, 129-139.

18. Mar, D. Design Examples Using Mode Shaping Spines for Frame and Wall Buildings. Proc. $9^{\text {th }}$ US National and $10^{\text {th }}$ Canadian Conference on Earthquake Engineering, Toronto, Canada, 2010; Paper No. 1400.

19. Hogg, S. Seismically Resilient Building Technology: Examples of resilient buildings constructed in New Zealand since 2013. Proc. $10^{\text {th }}$ Pacific Conference on Earthquake Engineering Building an Earthquake-Resilient Pacific, Sydney, Australia, 2015.

20. Latham, D.A., Reay, A.M., and Pampanin, S. Kilmore Street Medical Centre: Application of a post-tensioned steel rocking system. Proc. Steel Innovations Conference 2013, Christchurch, New Zealand, 2013.

21. Wiebe, L. Design and Construction of Controlled Rocking Steel Braced Frames in New Zealand, Proceeding of the Second ATC \& SEI Conference on Improving the Seismic Performance of Existing Buildings and Other Structures, San Francisco, California, USA, 2015 
22. Wiebe, L., and Christopoulos, C. Performance-Based Seismic Design of Controlled Rocking Steel Braced Frames. I: Methodological Framework and Design of Base Rocking Joint; II: Design of Capacity-Protected Elements. Journal of Structural Engineering 2015, 141 (9), DOI: 10.1061/(ASCE)ST.1943-541X.0001201-DOI: 10.1061/(ASCE)ST.1943-541X.0001202.

23. Gledhill, S. Practitioners guide to design and delivery of controlled rocking steel braced frame structures. Proc. Steel Innovations Conference 2015, Christchurch, New Zealand, 2015.

24. SCNZ. SCNZ - 110:2015, Design guide for controlled rocking systems. Steel Construction New Zealand, Manukau City, New Zealand, 2015.

25. NRCC. National Building Code of Canada (NBCC), $13^{\text {th }} \mathrm{ed}$., National Research Council of Canada (NRCC), Ottawa, ON, Canada, 2015.

26. ASCE. ASCE 41-13, Seismic Evaluation and Retrofit of Existing Buildings. ASCE, 2014.

27. CSI. SAP2000 Ultimate, Version 18. Computers and Structures, Inc., Berkeley, California, 2016.

28. NRCC. National Building Code of Canada (NBCC), $8^{\text {th }}$ ed., National Research Council of Canada (NRCC), Ottawa, ON, Canada, 1980.

29. CSA. CAN3-S16-M78 Steel Structures for Buildings- Limit State Design. Canadian Standards Association (CSA), Rexdale, ON, Canada 1978.

30. CSA. CSA-S16-14 Design of Steel Structures Canadian Standards Association (CSA), Rexdale, ON, Canada 2014.

31. Seo C-Y. 2005. Influence of ground motion characteristics and structural parameters on seismic response of SDOF systems. PhD Thesis, Lehigh University

32. Zhang C. Seismic Displacement Demands on Self-Centering Single-Degree-of-Freedom Systems. MASc Thesis, McMaster University, Hamilton, ON, Canada, 2015

33. Chopra, Anil K., et al. Dynamics of structures. New Jersey : Prentice Hall, 1995

34. Richard, J. Étude du comportement sismique de bâtiments industriels avec systèmes de contreventement en acier de faible ductilité : École polytechnique de Montréal, Montréal, QC, Canada, 2009

35. Tremblay, R., Atkinson, G. M., Bouaanani, N., Daneshvar, P., Léger, P., and Koboevic, S. Selection and scaling of ground motion time histories for seismic analysis using NBCC 2015. Proceeding $11^{\text {th }}$ Canadian Conference on Earthquake Engineering, Victoria, BC, Canada, Paper no. 99060, 2015.

36. NRCC. User's Guide - NBC 2015 Structural Commentaries, National Research Council of Canada (NRCC), Ottawa, ON, Canada, 2017.

37. Wiebe, L., and Christopoulos, C. A cantilever beam analogy for quantifying higher mode effects in multistorey buildings. Earthquake Engineering and Structural Dynamics 2015, DOI: 10.1002/eqe.2549.

38. Rogers, C.A., Marosi, M., Hertz, J., Lignos, D., Tremblay, R., and D’Aronco, M. Performance of weld-retrofit beam-to-column shear tab connections. Proceedings $8^{\text {th }}$ International Workshop on Connections in Steel Structures (Connections VIII), Boston, MA, 2016.

39. Steele TC, Wiebe LDA.. Dynamic and equivalent static procedures for capacity design of controlled rocking steel braced frames. Earthquake Engineering and Structural Dynamics, 2016, 45(15): 23492369, DOI 10.1002/eqe. 2765 